\title{
Observation and quantification of three-dimensional crack propagation in poly-granular graphite*
}

\author{
M. Mostafavi ${ }^{1 \dagger}$, S. A. McDonald ${ }^{2}$, P. M. Mummery ${ }^{3}$, T. J. Marrow ${ }^{1}$ \\ ${ }^{1}$ Department of Materials, The University of Oxford, UK \\ ${ }^{2}$ School of Materials, The University of Manchester, UK \\ ${ }^{3}$ School of Mechanical, Civil and Aerospace Engineering, The University of Manchester, UK
}

\begin{abstract}
Observations of fracture are generally restricted to the surface of test specimens; yet the fracture process occurs within the material. X-ray computed tomography (XCT) provides valuable insights into the structures within materials: when XCT is combined with digital volume correlation (DVC) the response to applied loads can be measured with high precision in the form of the threedimensional displacement field within the material. This paper reports a study of the fracture behaviour of a short-bar chevron notch crack propagation specimen fabricated from polygranular nuclear graphite - a quasi-brittle material. A three-dimensional linear elastic finite element simulation of the specimen obtained the relations between crack length, opening displacement and stress intensity factor along the crack front. Tomographic absorption contrast images were obtained from the specimen before and after crack propagation, whilst loaded. The DVC-measured displacement field was used to measure and map the crack opening displacements in 3D; the
\end{abstract}

* NOTICE: this is the author's version of a work that was accepted for publication in Engineering Fracture Mechanics. Changes resulting from the publishing process, such as peer review, editing, corrections, structural formatting, and other quality control mechanisms may not be reflected in this document. Changes may have been made to this work since it was submitted for publication. A definitive version was subsequently published in Engineering Fracture Mechanics 2013, http://dx.doi.org/10.1016/j.engfracmech.2012.11.023

\footnotetext{
${ }^{\dagger}$ Corresponding author; Department of Materials, Parks Road, University of Oxford, Oxford, UK OX1 3PH. Email: Mahmoud.mostafavi@materials.ox.ac.uk Phone: $+44(0) 1865283326$

Fax: +44 (0)1865 273789
} 
experimentally calculated crack opening displacements were consistent with the FE-predicted values. The measurements demonstrate the existence of a cohesive fracture process zone ahead of the crack tip, which is a characteristic of quasi-brittle materials. This suggests that simulation of the fracture of non-irradiated polygranular nuclear graphite requires a material model capable of showing softening behaviour.

Keywords: Nuclear graphite, computed X-ray tomography, digital volume correlation, crack propagation, fracture process zone

\section{Introduction}

Quasi-brittle fracture is an emergent characteristic of inhomogeneous brittle materials. For example, a simple network of individually brittle elements of variable strength will exhibit the characteristic damage tolerant and graceful failure of a quasi-brittle material; as loading progresses, failures of individual elements occur and coalesce to form cracks, while elastic strains are redistributed in the remaining structure. The cracks in the network reduce its stiffness and thereby influence its elastic strain energy. The network's ultimate failure depends on the balance between the release of this stored elastic energy and the energy absorbed by fractures of individual elements. The gracefulness of this failure is affected by the distributions of strength, stiffness and the connectivity of the brittle elements. These are properties of a quasi-brittle material's microstructure, and they have a direct effect on the strength and damage tolerance of structures, so studying the interactions between microstructure, damage and mechanical behaviour in such materials contributes to the improvement of their structural integrity assessment. Many materials show degrees of quasi-brittle behaviour: concrete [1], polygranular graphite [2], rocks [3], bone [4] and porous ceramics [5] to name a few. Graphite is an important component in several current and future designs of nuclear fission reactors, and the structural integrity of the graphite moderator is critical to the safe operation of the UK's Advanced Gas Reactors (AGR); radiolytic oxidation degrades nuclear graphite strength while amongst other effects the fast neutron irradiation causes dimensional changes. Ultimately their combined effect may develop tensile stresses sufficient to cause damage to the reactor core. It is important that structural integrity methods are developed that can take appropriate account of the damage mechanisms in the graphite.

Graphite is generally treated as a linear elastic material and its structural integrity is conservatively assessed using linear elastic fracture mechanics [6-9]. However, non-irradiated graphite may be 
regarded as a quasi-brittle material; there is clear evidence of the non-linear mechanical behaviour [10], a rising fracture resistance curve ( $J$-R curve) $[2,11]$ and also the development of a microcracked fracture process zone [12]. The effects of mechanical constraint on the fracture process zone may explain observed behaviours such as crack tunnelling [13] and also the effects of load biaxiality [14] and size [15] of both components and cracks [12] on structural integrity. An improved understanding of its fracture may give improved confidence in safety margins, and will aid the design of small-scale fracture specimens for measurement of the properties of irradiated graphites; irradiation tends to remove the non-linearity of mechanical behaviour [16], and inspection samples are necessarily limited in size.

The two-dimensional digital image correlation (DIC) technique has been used for quantitative insitu studies of damage nucleation and propagation in a range of materials $[14,17,18]$. Hild and Roux, for example, introduced a direct DIC method to calculate the stress intensity factors associated with a crack from the measured displacement field [19-21]. The measured displacement field can readily be converted into a strain field and, if the material constitutive law is known, the stress field and its associated energy may also be derived as a $J$-Integral [22]. DIC is confined to studies of damage nucleation and propagation on the surface of specimens: yet damage propagates within the specimen. Measurements of the full three-dimensional displacement field within the material by the three-dimensional digital volume correlation (DVC) technique [23-25] can provide further useful insights and quantitative measurements of the processes of damage development [2628].

In this paper, we demonstrate the suitability of combined X-ray computed tomography and digital volume correlation (DVC) to study three-dimensional crack initiation and propagation behaviour. As the main goal is to understand and characterize a 3D crack, the DVC and XCT techniques are explained briefly only; although each is a significant topic. A short bar chevron notched specimen, fabricated from non-irradiated virgin nuclear graphite, was used to propagate a stable crack. The variation of critical stress intensity factor for stable crack propagation along the crack front was obtained via a three-dimensional finite element simulation. The specimen underwent two cycles of loading and unloading, observed with XCT, to explore the effects of irrecoverable deformation. The displacements associated with the crack, in response to load, were measured by analysing the tomographic images with digital image volume correlation. 


\section{Methodology}

\subsection{Experiment}

The short-bar chevron notched specimen (Fig. 1) is a specimen geometry utilised in several fracture mechanics standards [29, 30]. This study followed the recommendations of the International Society of Rock Mechanics [30] as the material of interest has quasi-brittle characteristics. The specimen diameter was $25 \mathrm{~mm}$, with a notch angle of $54^{\circ}$ and width $1 \mathrm{~mm}$. The ligament length was $23 \mathrm{~mm}$ and the whole length of the specimen $35 \mathrm{~mm}$. It was loaded by inserting a sharp steel wedge (with an angle of $10^{\circ}$ ) into the notch (see Fig. 1b) to initiate a crack at the tip of the chevron notch that will propagate in stable equilibrium; care was taken in designing the wedge angle to prevent it contacting with the notch tip and to retain self-locking properties through friction. The screw-driven loading rig ("DEBEN machine") and part of the specimen can be seen in Fig. 1c. The Perspex tube is X-ray transparent, allowing live observations by radiography, followed by X-ray computed tomography scans. The experiment was carried out at the Manchester X-ray Imaging Facility (University of Manchester), using a $320 \mathrm{kV}$ Nikon Metris custom bay lab instrument at a voxel size of $8 \mu \mathrm{m}$ with a $2000 \times 2000$ pixel detector; 2000 radiographs were obtained over a $360^{\circ}$ rotation for each scan and reconstructed to obtain a three-dimensional absorption tomograph with a volume of approximately $16 \times 16 \times 16 \mathrm{~mm}$. Graphite has sufficiently low X-ray attenuation that the portions of the sample outside this region of interest did not significantly affect the reconstruction by standard back-projection algorithms; post-processing for the influence of sample geometry was therefore unnecessary. The initial CT scan was taken with the specimen inside the Perspex tube without any load. The wedge was then driven in the specimen, to initiate and propagate a crack, at a displacement rate of $0.1 \mathrm{~mm} / \mathrm{min}$. Two cycles of loading and unloading was performed. In the first cycle the wedge was driven until an applied load of $230 \mathrm{~N}$ was reached. With the wedge in place, a second CT scan was recorded (Fig. 1d shows a 3D visualisation of the cracked specimen at this stage). A third scan was performed after removal of the wedge; this completed the first loading cycle. The second loading cycle was similar to the first loading cycle, except the maximum load, was $266 \mathrm{~N}$. A final scan was taken after the removal of crack wake, using an electro-discharge machine $(E D M)$ with a wire diameter of $0.375 \mathrm{~mm}$ to a depth of $6 \mathrm{~mm}$ from the notch tip. This was done to examine the possible effects of asperities on the residual crack opening displacement. Examples of the reconstructed CT datasets are shown in 


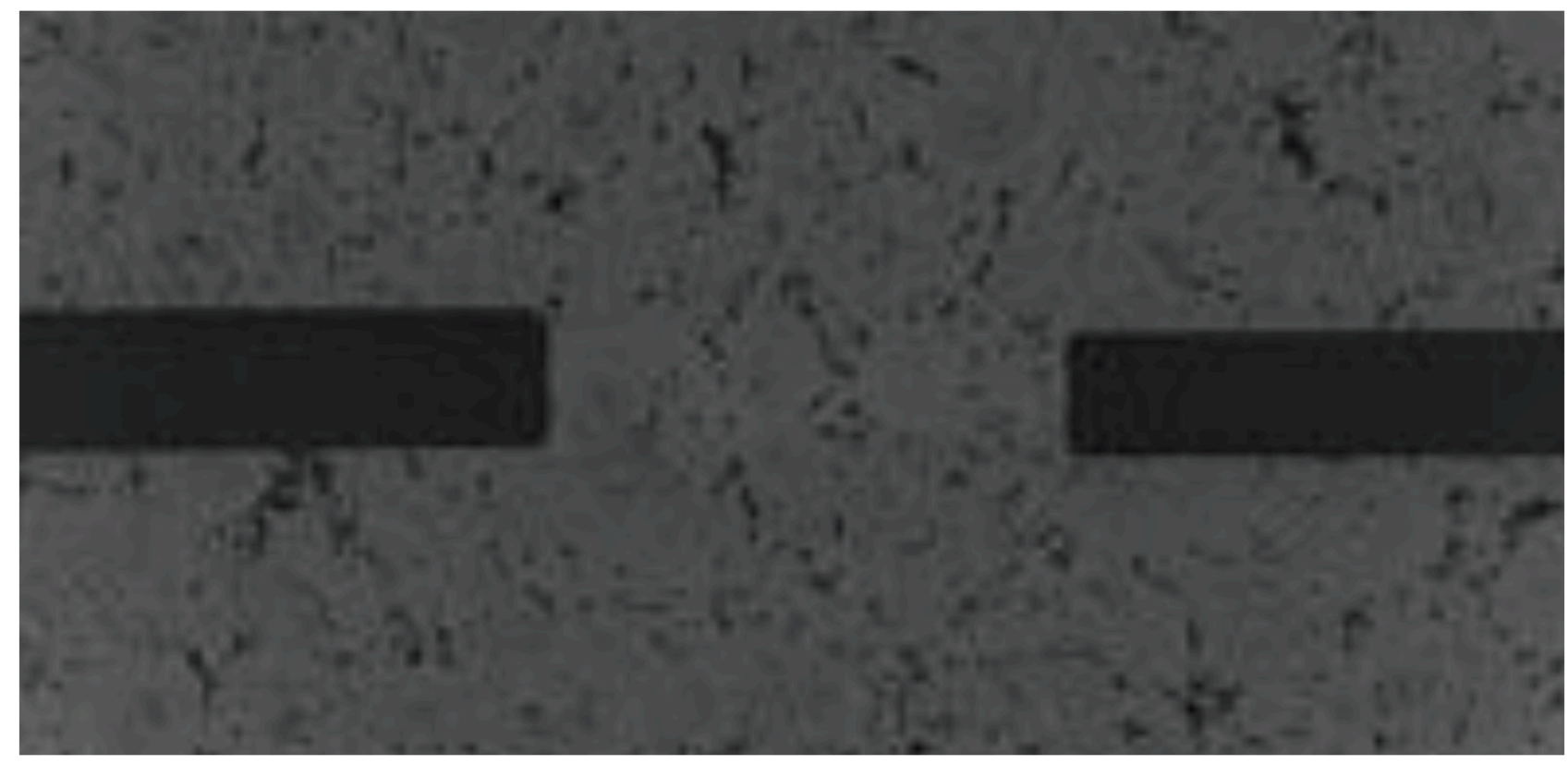

(a)

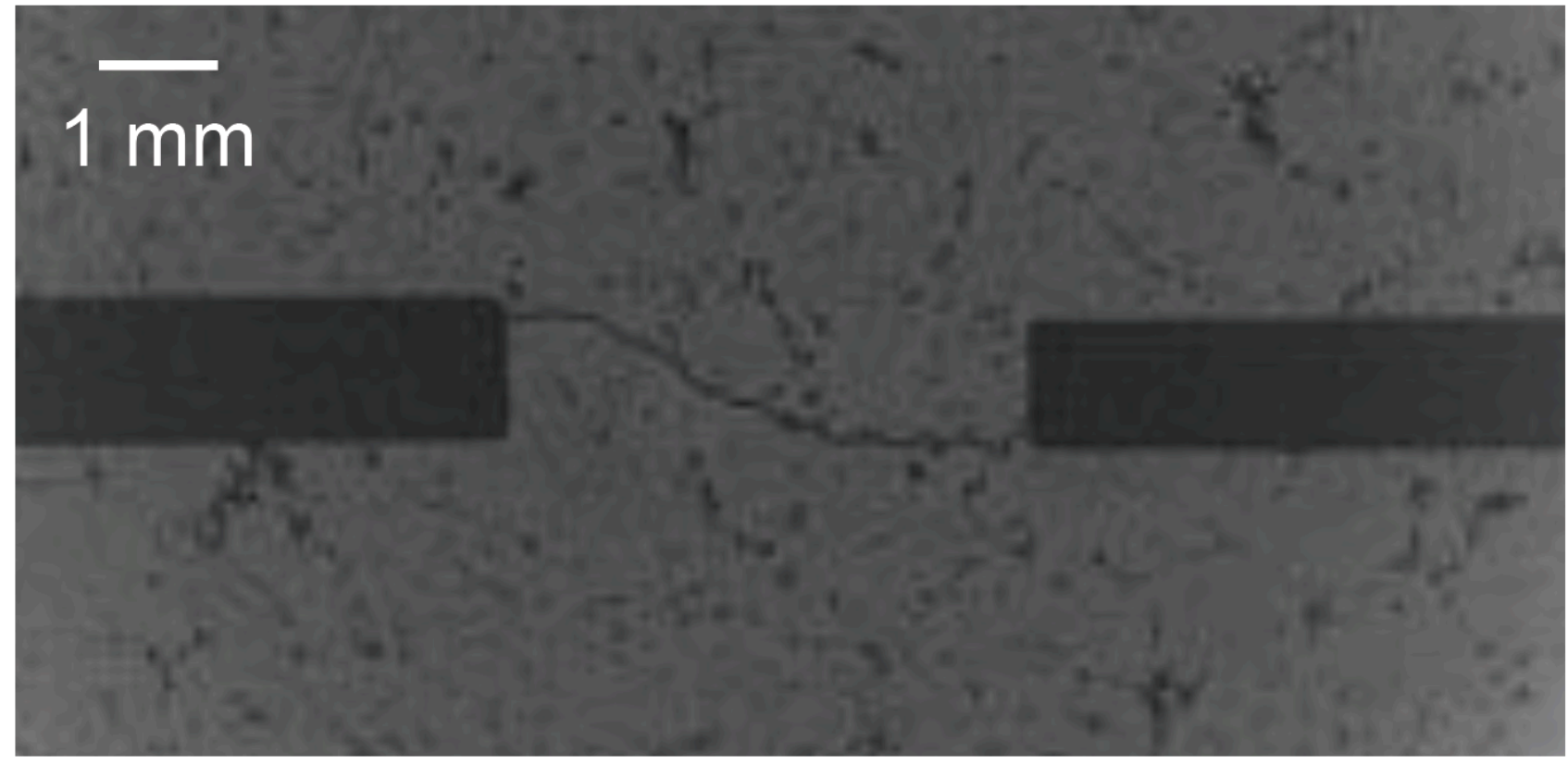

(b)

Fig. 2 for the first (unloaded) and second (loaded) CT scans of the first cycle.

The maximum loads at the end of cycle 1 and $3(230 \mathrm{~N}$ and $266 \mathrm{~N})$ were selected by monitoring of the specimen during the experiment. A preliminary finite element simulation performed in the design of the experiment with an assumed fracture toughness of $1.4 \mathrm{MPa} \cdot \mathrm{m}^{0.5}$ showed that the load 
required to propagate the crack would reach a maximum of approximately $250 \mathrm{~N}$. The loading towards this level was stopped $230 \mathrm{~N}$ during the experiment, since the load-displacement curve showed a significant deviation from linearity, which was taken as a sign of crack propagation. The reloading was suspended at $266 \mathrm{~N}$ during the experiment, again based on judgement of the deviation from linearity of the load displacement curve.

\subsection{Finite Element Analysis}

Two finite element analyses, defined as "whole" and "simple" were carried out to simulate the specimen using ABAQUS/Standard 6.9 [31]. An overview of both models, which used quadratic elements, is shown in Fig. 3(a and b). In both cases the elastic properties for typical near-isotropic nuclear graphite were assumed: Young's modulus, $10.9 \mathrm{GPa}$, and Poisson's ratio, 0.2 [32]. The elastic strain energy release rate ( $J$-integral) with crack propagation was calculated by ABAQUS by exploiting the contour integral method [31], from which the mode I stress intensity factor was obtained. Collapsed nodes or singular elements were not used at the crack front since they do not affect the energy release rate calculated [33] by the contour integral method [34].

In the whole model, the wedge was simulated as a rigid body in contact with the elastic graphite sample, which was fully modelled in 3D. A coefficient of friction of 0.1 was used to define the contact between the steel wedge and the specimen [35]. The whole model enabled the mode III contribution, induced by crack propagation at an angle across the chevron, to be obtained, and also included the effect on the in-plane constraint due to the compressive load from the loading wedge. The whole model was produced for one crack length $(\mathrm{a}=5 \mathrm{~mm})$ with a crack angle of $23^{\circ}$..

In the simple model, considering symmetry, only one quarter of the specimen was simulated with appropriate boundary conditions; the crack front was assumed to be straight, with no deviation from the specimen axis. The loading plane was assumed to be sufficiently far from the crack tip to neglect the local effects of contact between the steel wedge and specimen; hence the steel wedge and its contact with the specimen were not simulated. As the steel wedge is quite rigid compared to the graphite (the Young's modulus of steel is $\sim 200 \mathrm{GPa}$, compared to $\sim 11 \mathrm{GPa}$ for graphite [32]) the model was constrained so that nodes along the notch edge, which were all in contact with the wedge, were equally displaced in order to open the crack. The reaction load to the applied displacement, and hence the vertical load applied to the wedge, was obtained; this could then be compared with the experiment. The simple model was computationally efficient compared to the whole model, and 
nodes along the straight crack front were released manually, at $1 \mathrm{~mm}$ intervals in 22 steps from $a / W=0.043$ to 0.96 , to simulate the effect of crack propagation to different crack lengths.

\subsection{Digital Volume Correlation}

The digital volume correlation analysis was performed using the LaVision Davis Strain Master v. 8.0 [36] software. The CT datasets were correlated using a window size of $256 \times 256 \times 256$ voxels followed by $32 \times 32 \times 32$ voxels with $75 \%$ overlap; these parameters were chosen as the main objective was to extract the smooth displacement fields associated with the crack.

To estimate the random error in the digital volume correlation analysis, the background strain was measured in a region remote from the crack tip (i.e. $7 \mathrm{~mm}$ away from), where no deformation was expected and only rigid body movements occur; it was between $0.016 \%$ and $0.035 \%$ for the first four scans, which is equivalent to displacement noise of the order of 2.6 to $5.6 \mu \mathrm{m}$ (i.e. sub-pixel). However, for the scan performed after the removal of the crack wake, the random displacement error was measured in the same way to be $18 \mu \mathrm{m}$. This is noticeably greater than the other observations and is attributed to small changes in the sample-to-detector distance between the scans; due to the fan-beam geometry of the laboratory tomography equipment this affects the pixel magnification (by less than 5\%), but has a greater consequent effect on DVC precision.

\section{Results}

\subsection{Finite Element Analysis}

The linear elastic assumption of the FE model is considered valid in the wake of the crack, where stresses is low, as well as far ahead of the crack beyond any fracture process zone, hence the Jintegral may be obtained from the displacement fields, using contours that are sufficiently remote from the crack tip to provide a path independent value. Two sets of $J$-integral outputs may be obtained from the quadratic element FE analysis: one for the element corner nodes and the other at the mid-side nodes. Using the corner nodes has been shown to give a better representation of the energy release rate [37], thus data from these nodes were selected. The singularity of the stress field near the crack tip at a corner point (i.e. where the crack intersects the free surface of the specimen) differs from the theoretical $1 / \sqrt{r}$ ( $r$ is the distance from the crack tip) for materials with $v>0$. This has been discussed in detail by other researchers (e.g. Nakamura and Parks [38]). Stress intensity factors are defined to represent the magnitude of stress fields for a theoretical singularity and 
therefore are not a strictly appropriate measure of the crack severity in corner points. This problem has led some researchers to dismiss SIFs calculated at the corner points in FE analyses (e.g. Pook [39]). However, for a continuous crack front, a simple extrapolation of the SIF to the corner points has been suggested [40], and this approach has been used in this study.

The whole model was used to study the component of the mode III (out-of-plane shear) stress intensity factor in the equivalent stress intensity factor and to evaluate its significance in this experiment. As can be seen in

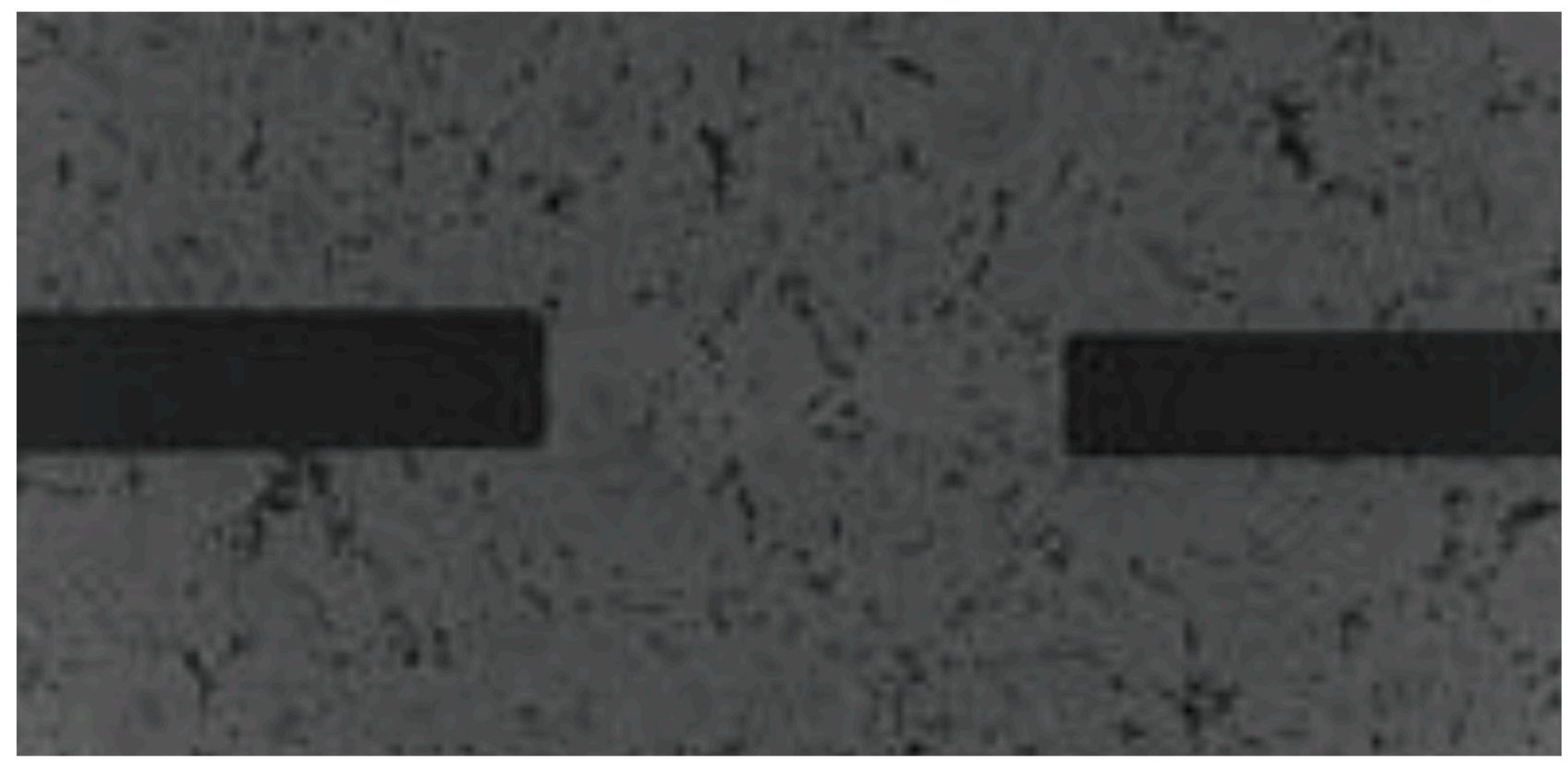

(a) 


\section{$1 \mathrm{~mm}$}

(b)

Fig. 2b, the crack propagates in an angle across the width of the chevron notch; the average angle decreases from $23^{\circ}$ to $0^{\circ}$ as the crack extends and widens. As an example, a $5 \mathrm{~mm}$ long, $23^{\circ}$ crack was introduced in the whole model and mode I and mode III stress intensity factors were calculated by ABAQUS. The analysis showed that the ratio of mode I to mode III stress intensity factor varied along the crack front, with its minimum value in the middle (approximately $4.5 \%$ ) and maximum on the outer edge (approximately 12\%). The mode III contribution is therefore concluded to be sufficiently small for it to reasonably be ignored in the equivalent stress intensity factor.

In order to evaluate the in-plane constraint level in both the whole and simple models, the nonsingular term of stress, i.e. $T$-stress, was considered [41]. The $T$-stress varies along the crack front, similarly to the stress intensity factor (see below), but its average provides an estimate of the general level of in-plane constraint. The $T$-stress is usually normalised and presented as the biaxiality ratio $\beta:$

$$
\beta=\frac{T \sqrt{\pi a}}{K}
$$

where $K$ is the stress intensity factor and $T$ is the $T$-stress. The average biaxiality ratio in the simple model is 0.43 and in the whole model is 0.27 . As both values are positive and as high constraint levels have little effect on the fracture behaviour (unless it is too large [42]), it can be concluded that 
the effect of simplifying the model has a negligible effect. Consequently, the simple model provides a sufficient description of the experiment and its results are used in this research here after.

The crack opening displacement, normalised with respect to the crack mouth opening displacement (COD/CMOD), is shown in Fig. 3b for different crack lengths. Fig. 3c illustrates the linear variation of the COD/CMOD vs. crack length gradient; the error bars demonstrate the deviation of the COD/CMOD - $x / a$ relation from a straight line, and are obtained as the standard deviation from the fitted line of the COD/CMOD $-x / a$ curve. For crack lengths with a $>4 \mathrm{~mm}$ (i.e. for $x /(W-a)>0.4)$, the normalised crack opening displacement is linear with $95 \%$ confidence with a gradient that varies with the crack length (Fig. 3c). Thus, the experimentally measured gradient of the crack opening displacement may be used to estimate the elastic crack length.

The mode I stress intensity factor, obtained via the $J$-integral, varies along the crack front, with a minimum at the centre. There is a significant difference for smaller crack lengths: $K_{\max } / K_{\min }=1.66$ for $a / W=0.043$, which decreases with increasing $a / W$; for instance to 1.12 for $a / W=0.65$ and to less than $10 \%$ difference for $a / W>0.65$. The variation of normalised stress intensity factor, $K_{N}$ along the normalised crack front, $\bar{y}$, is shown in Fig. $3 \mathrm{~d}$ with increasing crack length. The implication of this analysis is that cracks initiated at the tip of the chevron may be expected to exhibit an initially concave crack front, which will straighten with further propagation.

$$
\begin{aligned}
& K_{N}=\frac{K}{\sigma \sqrt{a}} \\
& \bar{y}=\frac{y}{l}
\end{aligned}
$$

where $\sigma$ is the nominal opening stress $(\sigma=F / A ; \mathrm{F}$ is the applied force and $A$ is the area of the ligament ahead of the crack front), $y$ is the distance from the middle of the crack and $l$ is the length of the crack front (see Fig. 1b).

\subsection{Digital Volume Correlation}

An example 2D slice through the 3D displacement data is shown in Fig. 4a, with a visualisation of the crack opening using the maximum normal strain that is obtained from the displacement gradients. The DVC data allow the crack opening displacement under load to be measured. Its variation across the crack surface was mapped: to do this efficiently for the large number of measurements, the displacement vectors along a line orthogonal to the notch plane were extracted at 
each point; a fifth-order polynomial was fitted to the displacement vector component along the line and the difference between its maximum and minimum was taken as the crack opening displacement (COD). The data are shown in Fig. 5, which illustrates the crack opening is greatest close to the notch tip, as to be expected, and that the crack front is uneven. The white patches in Fig. 5 are caused by volumes in the vicinity of the crack where the coefficient of correlation was less than 0.5 (this is generally caused by local image artefacts in the tomographic reconstruction); the crack opening displacement data at these locations are unreliable, and so were excluded from the subsequent calculations of crack opening profile (average and standard deviation).

Data for the average crack opening displacement under both loaded and unloaded conditions for the two load cycles are shown in Fig. 6. The average was calculated along lines parallel to the specimen axis, for comparison with the finite element simulation; only average for every five values is shown. The COD values, normalised by the CMOD, are presented in Fig. 7 together with data for FE simulations obtained using the estimated physical crack length. The crack mouth opening displacement was not measured in this experiment (it was beyond the observed volume) but was extrapolated from the linear region of COD; the extrapolated CMOD values are $5.3 \times 10^{-2}, 9.4 \times 10^{-4}$, $1.15 \times 10^{-1}$, and $1.04 \times 10^{-3} \mathrm{~mm}$ respectively for the loaded and unloaded conditions at the first and second loading cycles. The gradient, measured between $x=2 \mathrm{~mm}$ and $x=4 \mathrm{~mm}$, of the normalised crack opening displacement (COD/CMOD vs. $x /(W-a)$, as described in section 3.1) was used to estimate the physical crack length, which was $5.7 \pm 0.15 \mathrm{~mm}$ (gradient $1.24 \pm 0.008$ ) in the first and $6.2 \pm 0.4 \mathrm{~mm}$ (gradient $1.2 \pm 0.0018$ ) in the second cycle. For comparison, using visual examination of the contrast in the CT images alone with the crack under load, the observed crack length at the specimen centre is $4.8 \pm 0.2 \mathrm{~mm}$ for the first and $6.1 \pm 0.4 \mathrm{~mm}$ for the second cycle (see Fig. $5 \mathrm{~b}$ and d). The crack could not be visualised by image contrast in the unloaded condition.

The data in Fig. 7 show a substantial zone (of the order of $2 \mathrm{~mm}$ in length) ahead of the physical crack tip position, where there is a measureable opening displacement that is significant compared to the background noise (uncertainty in the data). This is most clear in the loaded conditions, and was not observed in the unloaded condition after the crack wake had been removed; the wake was cut out to the position $x=6 \pm 0.3 \mathrm{~mm}$. 


\section{Discussion}

Digital volume correlation analysis of X-ray computed tomography data has been employed to study the 3D opening of a crack, propagated in a short-bar chevron notch specimen. The crack can be readily visualised as a region of high artificial strain, due to its opening displacement. Comparison of the crack length measurements by visual observation of the crack (in the CT data) and the crack opening displacement data (Fig. 5) shows that DVC is more sensitive than XCT in visualising the crack. This is consistent with previous $2 \mathrm{D}$ studies $[11,12]$; simple visualisation by contrast cannot reliably detect crack openings that are much less than one pixel, whereas DVC may measure subpixel displacements. The crack opening displacements map (Fig. 5) shows the crack tends to open more towards one edge. This suggests a slight misalignment of the loading wedge, and further demonstrates the sensitivity of DVC measurements; the variation is less than $0.2 \mathrm{~mm}$ over a distance of over $6 \mathrm{~mm}$, for example. The uneven crack front is attributed to local interactions with the coarse nuclear graphite microstructure, which contains Gilsonite coke particles up to $1 \mathrm{~mm}$ in size [32].

Fitting the measured opening displacements to the FE simulation (Fig. 7), as describe in the previous section, gives an average stress intensity factor, $K=1.60 \mathrm{MPa} \cdot \mathrm{m}^{1 / 2}\left(1.50\right.$ to $1.68 \mathrm{MPa} \cdot \mathrm{m}^{1 / 2}$ with $95 \%$ confidence) for the first cycle at peak load and $K=1.71 \mathrm{MPa} \cdot \mathrm{m}^{1 / 2}\left(1.65\right.$ to $1.77 \mathrm{MPa} \cdot \mathrm{m}^{1 / 2}$ with $95 \%$ confidence) for the second loading cycle. These are similar to data obtained in different specimen geometries of the same material; toughness values of 1.4 and $1.2 \mathrm{MPa} . \mathrm{m}^{1 / 2}$ have been reported [12, 13]. Differences may arise from the R-curve behaviour of graphite, which depends on specimen geometry [11].

The residual opening of the crack after unloading the specimen (i.e. removing the wedge) introduces a small residual stress intensity factor, measured to be $0.02 \pm 0.015 \mathrm{MPa} . \mathrm{m}^{1 / 2}$ for the first and $0.03 \pm 0.03 \mathrm{MPa} \cdot \mathrm{m}^{1 / 2}$ for the second loading cycle. The crack wake was removed to investigate whether this was due to asperities preventing the crack from closing completely, or inelastic behaviour ahead of the crack tip (i.e. permanent damage). No residual stress intensity factor could be obtained; the opening displacements were measured to be $18.2 \pm 5.2 \mu \mathrm{m}$. However, this is of the order of the experimental uncertainty, and the observation was therefore inconclusive. The small magnitudes of the displacements suggest that the dominant cause of the residual stress intensity factor is roughness-induced closure, i.e. the crack does not fully close due to contact between the surfaces. This will be examined in future, higher resolution, experiments. 
Although the open crack behaves elastically, Fig. 5 shows that a continuous crack front cannot be defined that separates the cracked and uncracked regions. This is due to the development of a microcracked fracture process zone ahead of the fully open crack [14]; its elastic relaxation on the removal of load is seen in Fig. 7. The observed crack opening profile, which is equivalent to the classical strip-yield model, suggests that a cohesive model, defined by a traction-separation law, will be a better representative of the mechanical behaviour of graphite compared to the conventional linear elastic approach. This is consistent with previous experimental observations showing the non-negligible effects of microcracking [11] as well as our previous modelling attempts [14]. Comprehensive work is underway to exploit a softening behaviour of cohesive models in simulating the fracture behaviour of graphite components for different loading conditions and geometries.

The stress intensity factors obtained here, by fitting the linear elastic FE simulation to the crack opening profile, are approximations. The authors suggest that a more accurate and direct calculation of energy release rate, which is the thermo-dynamic mechanical driving force for crack propagation, is required. Such a method, that is not dependent on accurate location of the crack tip, is desirable since an asymptotic stress, strain or displacement distribution cannot be accurately fitted to the experimental measurements. Methods based on fitting the asymptotic fields have been applied in other materials (e.g. [43]), but they require the crack tip position to be defined with confidence [11], and may therefore not be applied in cases where there is a substantial fracture process zone. A methodology has been developed by the authors to calculate the elastic strain energy release rate from direct digital image correlation observations in 2D [22], based on the contour integral method [34]; this is now being developed for 3D application and will be reported in a future publication.

\section{Concluding Remarks}

- Digital volume correlation was successfully applied on the XCT data of nuclear graphite and allowed quantification of the full-field crack parameters (e.g. length and toughness).

- Strip-yield type opening ahead of the crack tip was observed, providing further evidence for the quasi-brittle behaviour of graphite due to microcracking initiating in the fracture process zone. 


\section{Acknowledgements}

We acknowledge funding from the EPSRC for the X-ray imaging facility under EP/F007906/1 and EP/F028431/1. Ms A. Fargette is thanked for her assistance with the tomography experiment. TJM and MM acknowledge the support of the Oxford Martin School and EDF Energy (GRA/GNSR/6041). The opinions expressed are those of the authors and not necessarily those of EDF Energy. Dr R. Boardman and Professor I. Sinclair, $\mu$ Vis centre, University of Southampton, are gratefully acknowledged for their assistance with $3 \mathrm{D}$ visualization of the strain data.

\section{References}

[1] Karihaloo BL. Fracture Mechanics and Structural Concrete. New York: Longman Scientific and Technical Publishers; 1995.

[2] Ouagne P, Neighbour GB, McEnaney B. Crack growth resistance in nuclear graphites. Journal of Physics D: Applied Physics. 2002;35:927-34.

[3] Aliha MRM, Ayatollahi MR, Smith DJ, Pavier MJ. Geometry and size effects on fracture trajectory in a limestone rock under mixed mode loading. Eng Fract Mech. 2010;77:2200-12.

[4] Vashishth D. Rising crack-growth-resistance behavior in cortical bone: implications for toughness measurements. Journal of Biomechanics. 2004;37:943-6.

[5] Lange DA, Jennings HM. Relashionship between fracture surface roughness and fracture behavior of cement paste mortar. Journal of American Ceramic Society. 1993;76:589-97.

[6] Ayatollahi MR, Berto F, Lazzarin P. Mixed mode brittle fracture of sharp and blunt V-notches in polycrystalline graphite. Carbon. 2011;49:2465-74.

[7] Ayatollahi MR, Torabi AR. Tensile fracture in notched polycrystalline graphite specimens. Carbon. 2010;48:2255-65.

[8] Burchell TD. A microstructurally based fracture model for polygranular graphites. Carbon. 1996;34:297-316.

[9] Tucker MO, McLachlan N. Fracture and microstructure of graphite. Journal of Physics D: Applied Physics. 1993;26:893-907.

[10] Neighbour GB, McEnaney B, Philips M. Acoustic emission responses from cyclic loading of a nuclear graphite. Carbon. 1992;30:359-62.

[11] Becker TH, Marrow TJ, Tait RB. Damage, crack growth and fracture characteristics of nuclear grade graphite using the Double Torsion technique. J Nucl Mater. 2011;414:32-43. 
[12] Mostafavi M, Marrow TJ. Quantitative in situ study of short crack propagation in polygranular graphite by digital image correlation. Fatigue and Fracture of Engineering Materials and Structures. 2012;35:695-707.

[13] Marrow TJ, Hodgkins AD, Joyce MR, Marsden BJ. Damage nucleation in nuclear graphite. En Mat. 2006;1:167-70.

[14] Mostafavi M, Marrow TJ. In situ observation of crack nuclei in poly-granular graphite under ring-on-ring equi-biaxial and flexural loading. Eng Fract Mech. 2011;78:1756-70.

[15] Darby MI. A fracture mechanics approach to the failure of graphite in laboratory tests. Int J Fract. 1976;12:754-7.

[16] Hull D, Mogford IL. Ductile-brittle transition in steels irradiated with neutrons. Philos Mag. 2958;3:1213-22.

[17] Cook A, Duff J, Stevens N, Lyon S, Sherry AH, Marrow TJ. Preliminary evaluation of digital image correlation for in-situ observation of low temperature atmospheric-induced chloride stress corrosion cracking in austenitic stainless steels. ECS Trans. 2010;25:119-32.

[18] Marrow TJ, Gonzalez D, Aswad M, Da Fonseca JQ, Withers PJ. In-situ observation and modelling of intergranular cracking in polycrystalline alumina. Key Eng Matter. 2011;465:507-10.

[19] Hild F, Roux S. Measuring stress intensity factors with a camera: Integrated image correlation (I-DIC). Comptes Rendus de l'Academie des Sciences Serie II b/Mecanique. 2006;334:8-12.

[20] Roux S, Hild F. Stress intensity factor measurements from digital image correlation: postprocessing and integrated approach. Int J Fract. 2006;140:141-57.

[21] Hamam R, Hild F, Roux S. Stress intensity factor gauging by digital image correlation: Application in cyclic fatigue. Strain. 2007;43:181-92.

[22] Becker TH, Mostafavi M, Tait RB, Marrow TJ. An Approach to Calculate the J-Integral by Digital Image Correlation Displacement Field Measurement Fatigue and Fracture of Engineering Materials and Structures. 2012;In press.

[23] Bay BK, Smith TS, Fyhire DP, Saad M. Digital volume correlation: three-dimensional strain mapping using X-ray tomography. Exp Mech. 1999;39:217-26.

[24] Franck C, Hong S, Maskarinec SA, Tirrell DA, Ravichandran G. Three-dimensional full-field measurements of large deformations in soft materials using confocal microscopy and digital volume correlation. Exp Mech. 2007;47:427-38.

[25] Smith TS, Bay BK, Rashid MM. Digital volume correlation including rotational degrees of freedom during minimization. Exp Mech. 2004;42:272-8.

[26] Forsberg F, Mooser R, Arnold M, Hack E, Wyss P. 3D micro-scale deformations of wood in bending: Synchrotron radiation 1CT data analyzed with digital volume correlation. JOURNAL OF STRUCTURAL BIOLOGY. 2008;164:255-62. 
[27] Forsberg F, Sjödahl M, Mooser R, Hack E, Wyss P. Full Three-Dimensional Strain Measurements on Wood Exposed to Three-Point Bending: Analysis by Use of Digital Volume Correlation Applied to Synchrotron Radiation Micro-Computed Tomography Image Data. Strain. 2010;46:47-60.

[28] Réthoré J, Limodin N, Buffière JY, Roux S, Hild F. Three-dimensional analysis of fatigue crack propagation using X-Ray tomography digital volume correlation and extended finite element simulations. PROCEDIA IUTAM. 2012;4:151-8.

[29] ASTM-E1304-97. Standard method for plane-strain (chevron-notch) fracture toughness of metallic mterials2002.

[30] Ouchterlony F. International society for rock mechanics commission on testing methods Suggested methods for determining the fracture toughness of rock. INTERNATIONAL JOURNAL OF Rock Mechanics and Mining Sciences. 1988;25:71-96.

[31] ABAQUS. User's Manual: ABAQUS Inc., Providence, Rhode Island, Version 6.9; 2009.

[32] Joyce MR, Marrow TJ, Mummery PM, Marsden BJ. Observation of microstructure deformation and damage in nuclear graphite. Eng Fract Mech. 2008;75:3633-45.

[33] Sinclair GB. Some inherently unreliable practices in present day fracture mechanics. Int J Fract. 1985;28:3-16.

[34] Li FZ, Shih CF, Needleman A. A comparison of methods for calculating energy release rates. Eng Fract Mech. 1985;21:405-21.

[35] Shi L, Zou Z, Fok ASL, Marsden BJ, Hodgkins AD, Mummery PM, et al. Analysis of crack propagation in nuclear graphite using three-point bending of sandwiched specimens. J Nucl Mater. 2008;372:141-51.

[36] LaVision. Digital Volume Correlation - DAVIS 8.0 Product Manual Gottingen2010.

[37] Brocks W, Scheider I. Numerical aspects of the path-dependece of the $J$-integral in incremental plasticity - How to calculate reliable $J$-values in FE analyses. Köln-Porz: Institute für Werkstofforschung; 2001.

[38] Nakamora T, Parks D. Three-dimensional stress field near the crck front of a thin elastic plate. J App Mech. 1988;55:805-14.

[39] Pook LP. Some implications of corner point singularities. Eng Fract Mech. 1994;48:367-78.

[40] Pook LP. A note on corner point singularities. Int J Fract. 1992;53:R3-8.

[41] Betegon C, Hancock W. Two parameter characterization of elastic-plastic crack tip fields. Journal of Applied Mechanics. 1991;58:104-10.

[42] Ayatollahi MR, Pavier MJ, Smith DJ. Mode I cracks subjected to large T-stresses", International Journal of Fracture. Int J Fract. 2002;117:159-74. 
[43] Yusof F, Withers PJ. Real-time acquisition of fatigue crack images for monitoring crack-tip stress intensity variations within fatigue cycles. J Strain Anal Eng Des. 2008;44:149-58. 
Figures

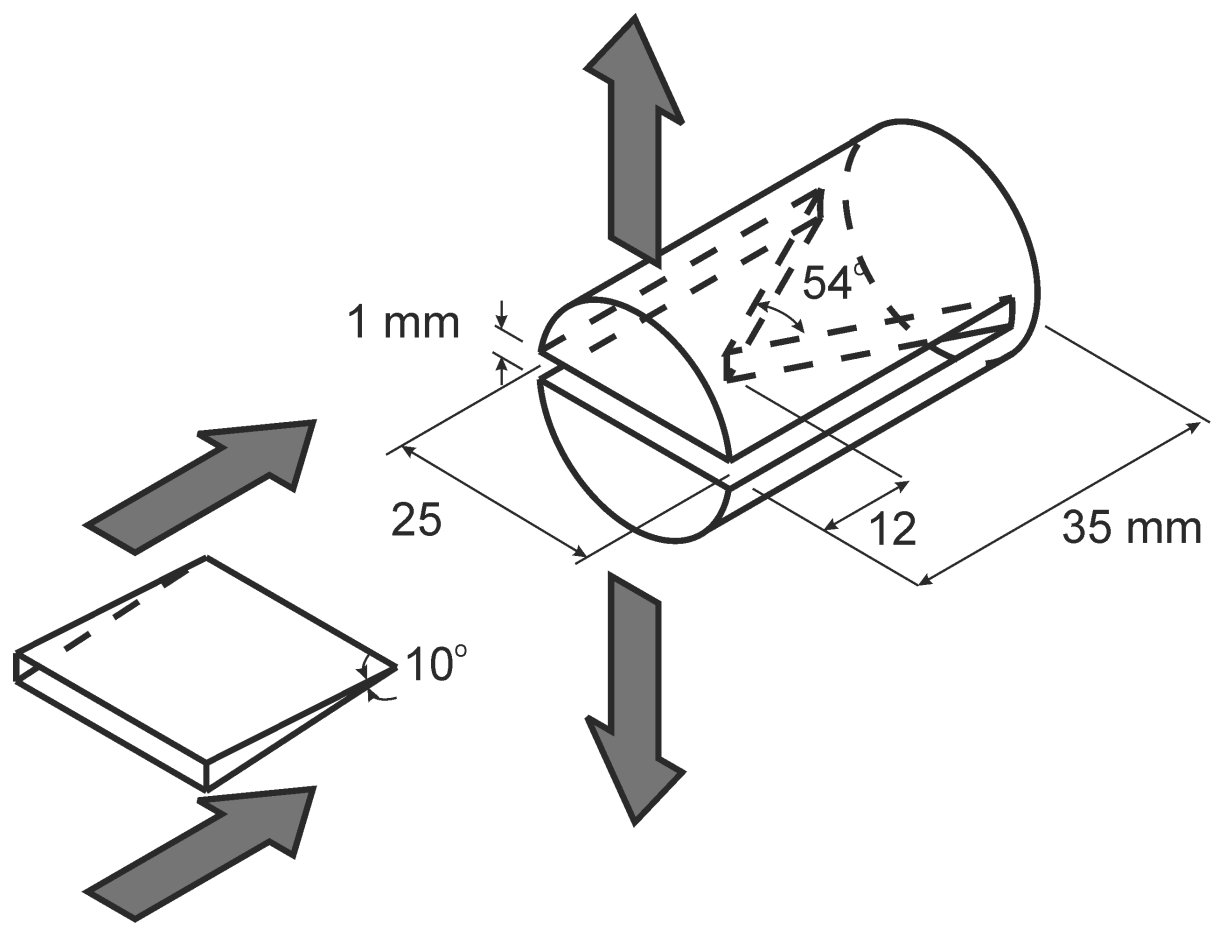

(a)

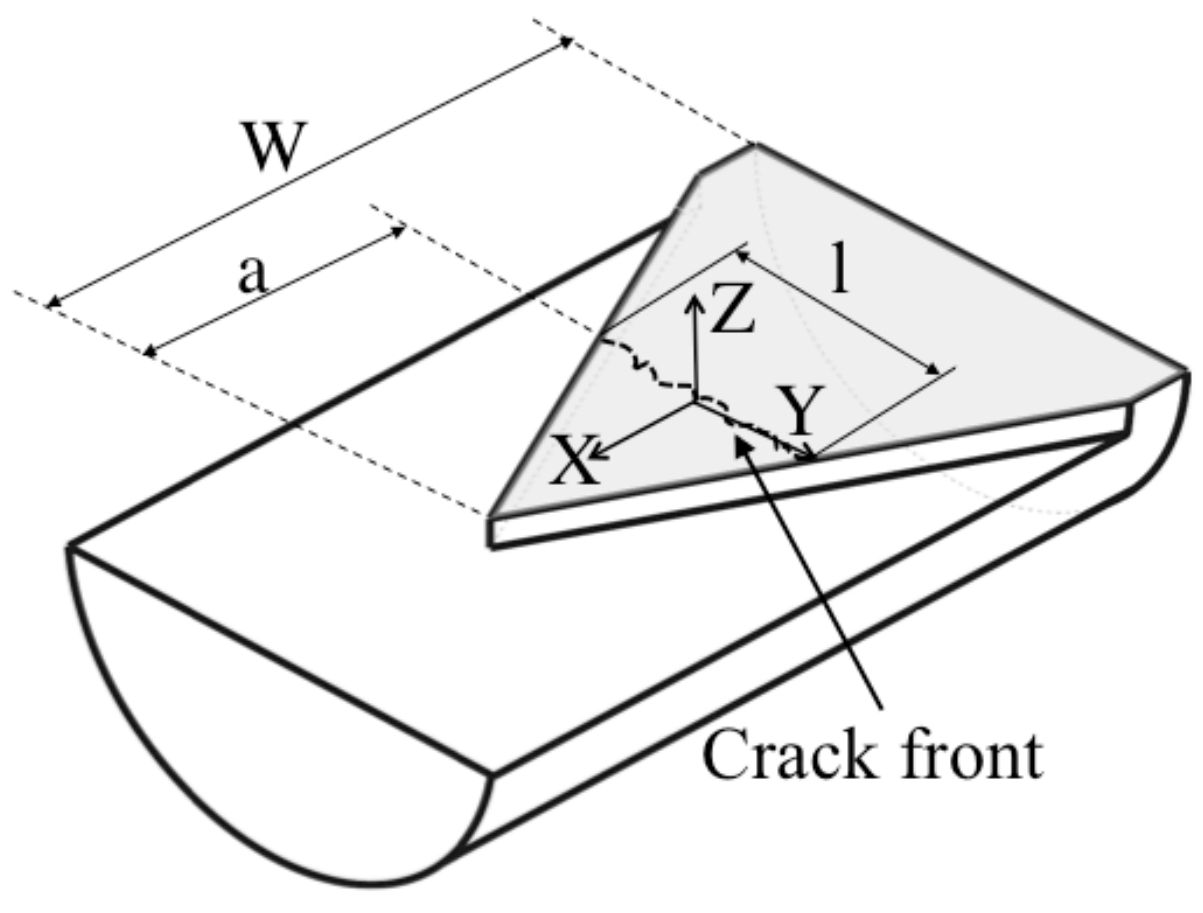

(b) 


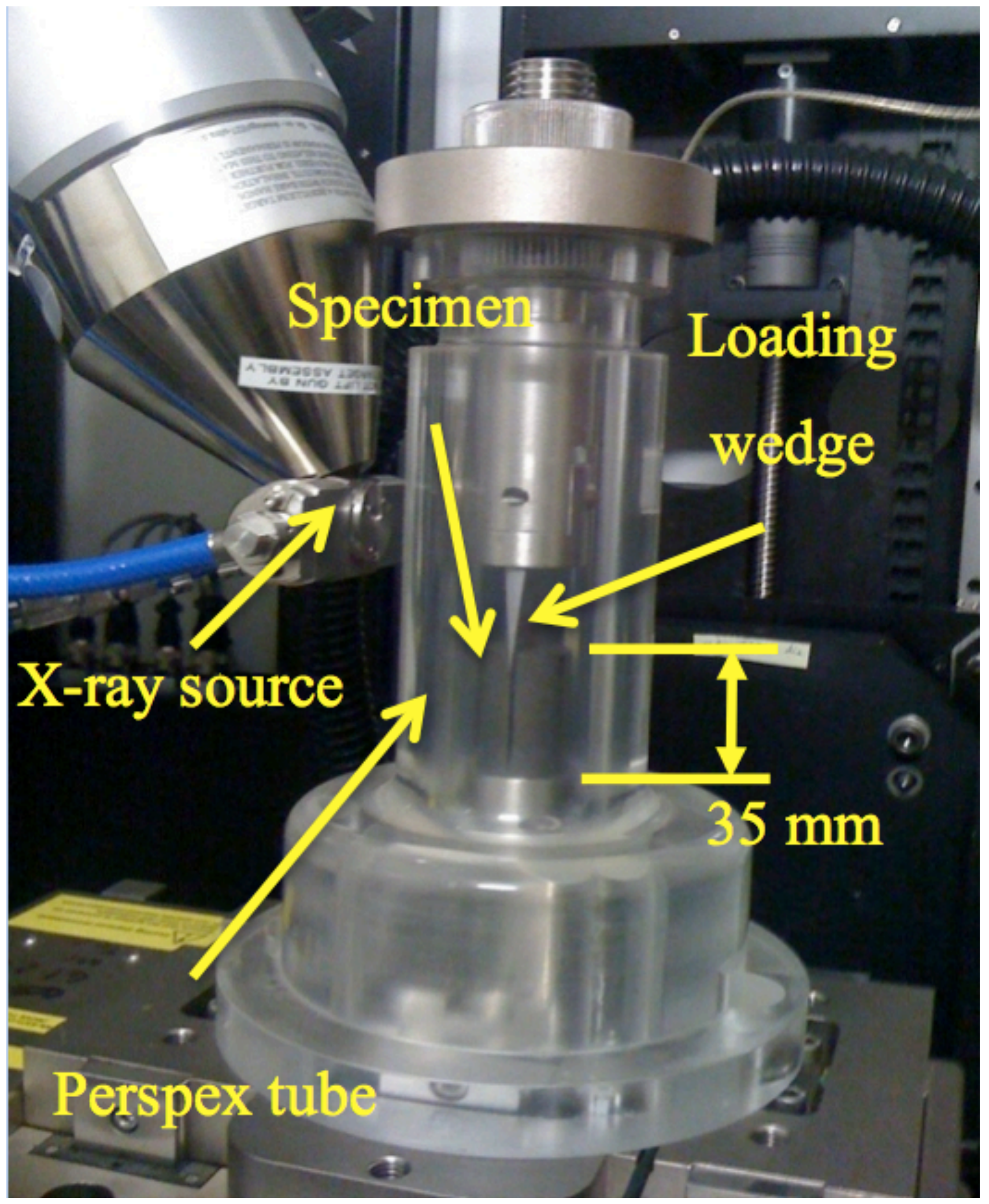

(c) 


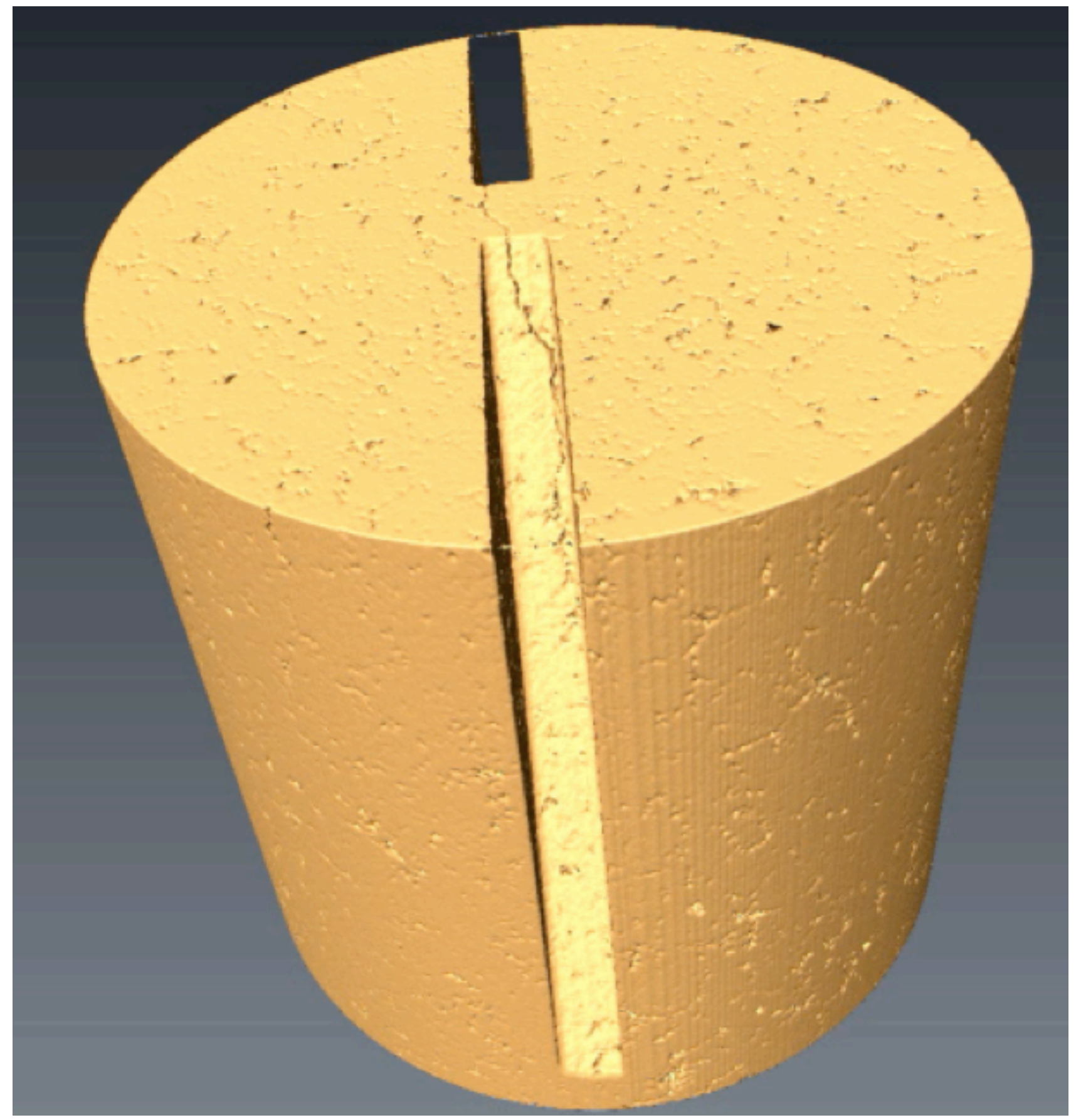

(d)

Fig. 1. Overview of the short-bar chevron notch specimen (a) dimensions of the specimen (b) half the specimen - the crack initiates from the notch tip and propagates toward the end the specimen (c) specimen within the loading rig (d) reconstructed tomography of the investigated region of the specimen after loading. 


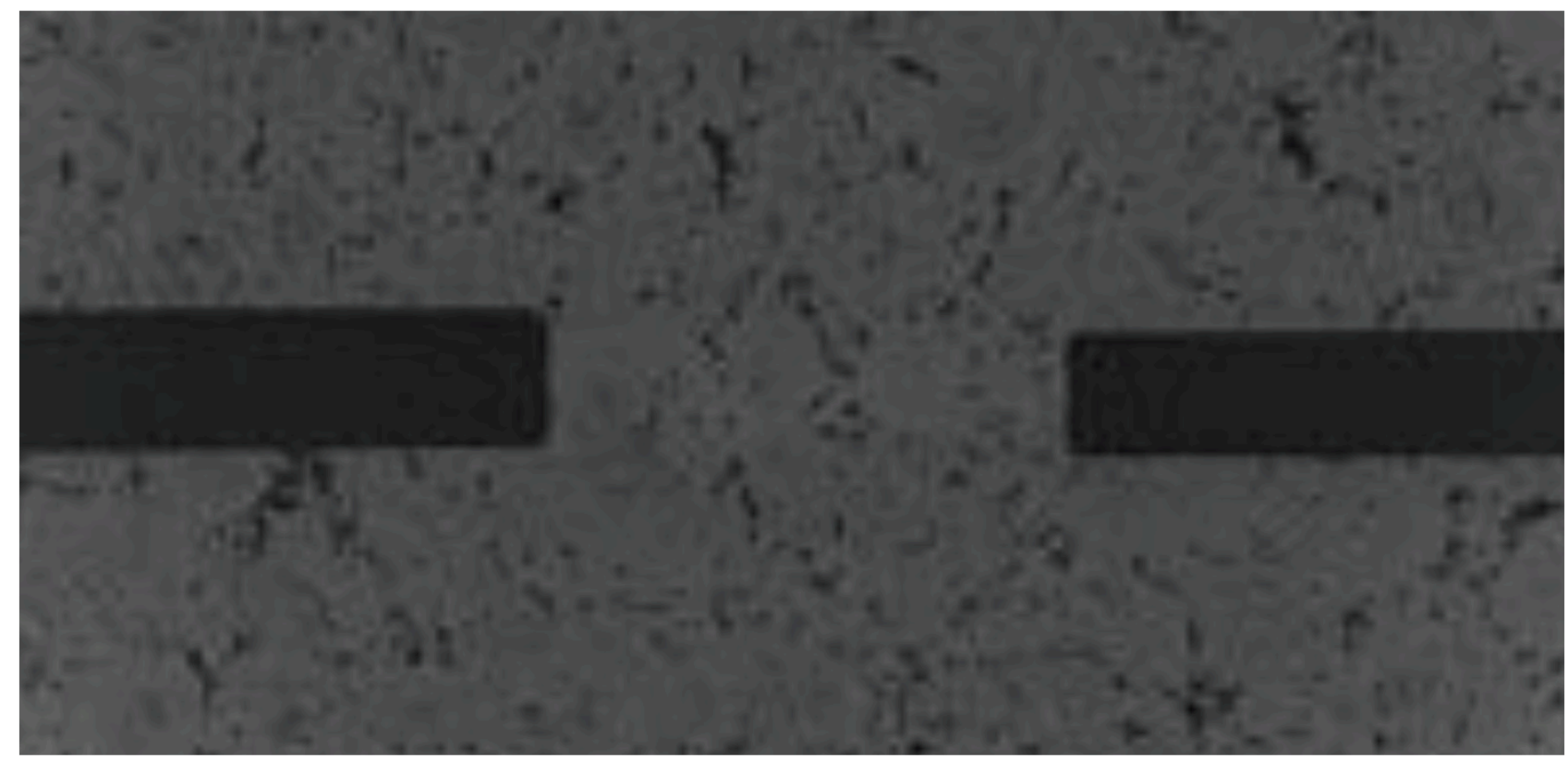

(a)

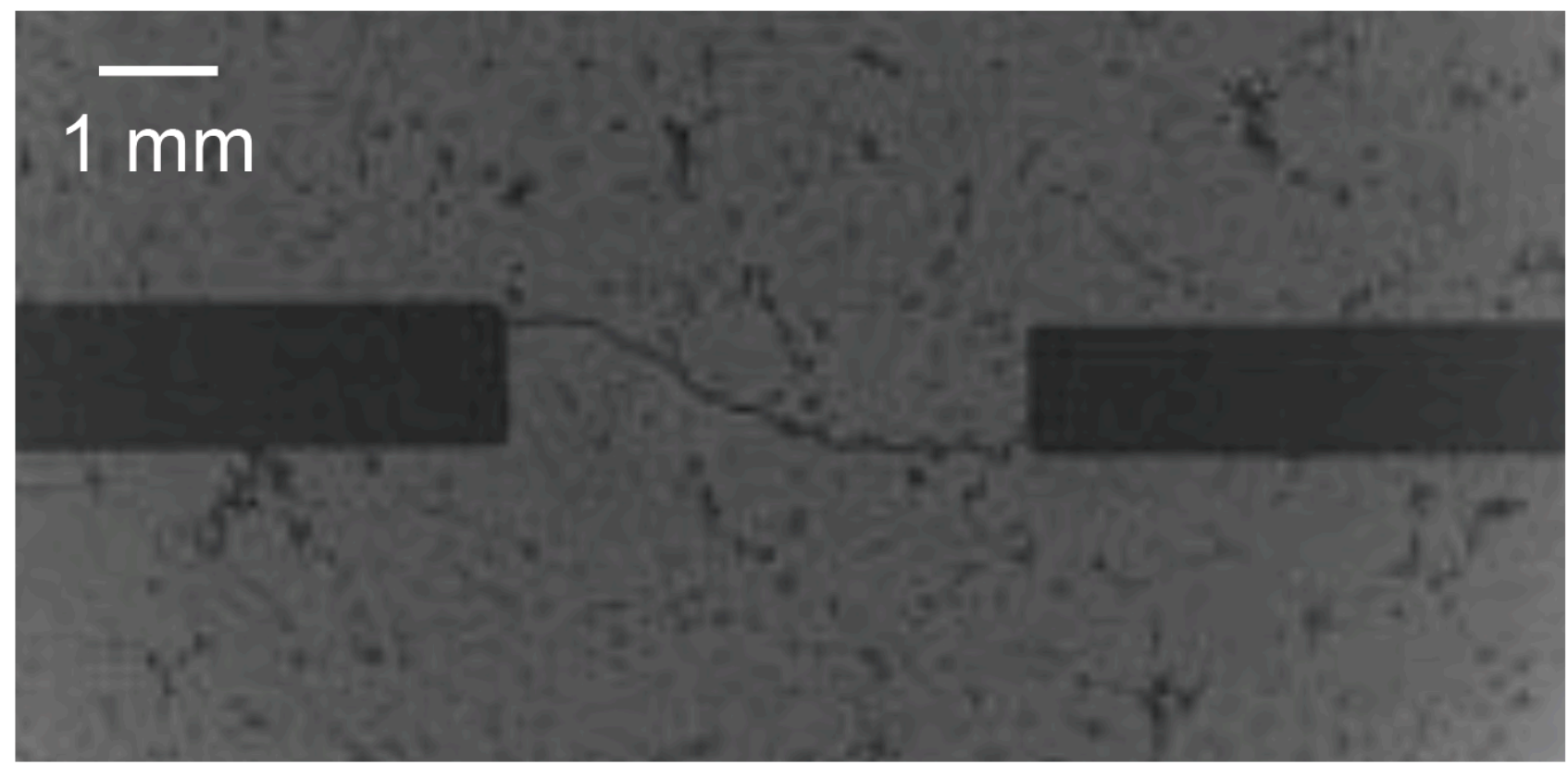

(b)

Fig. 2. XCT data (virtual sections in the YX plane, $3 \mathrm{~mm}$ below the notch tip); (a) before loading (b) loaded. 


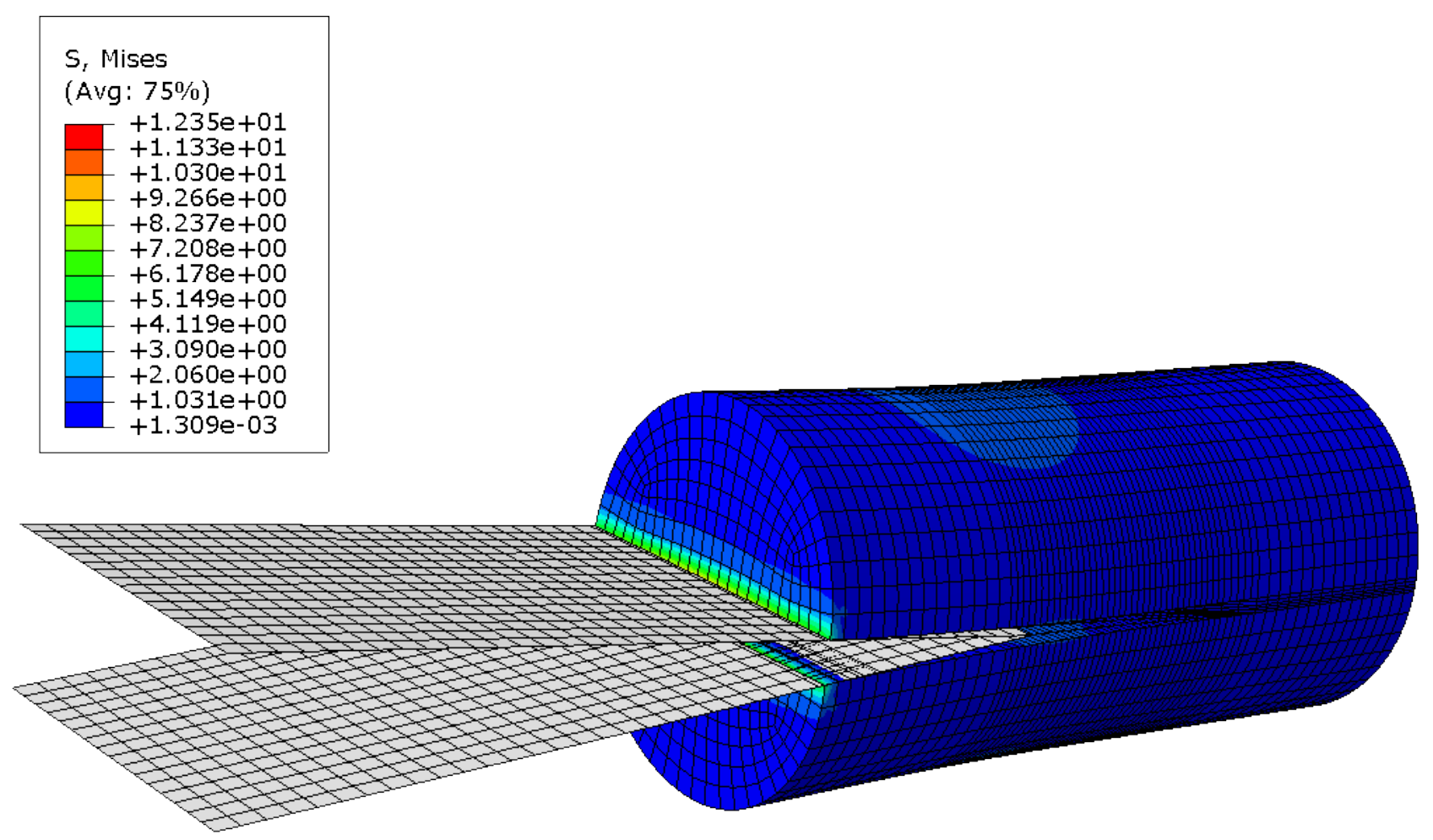

(a)

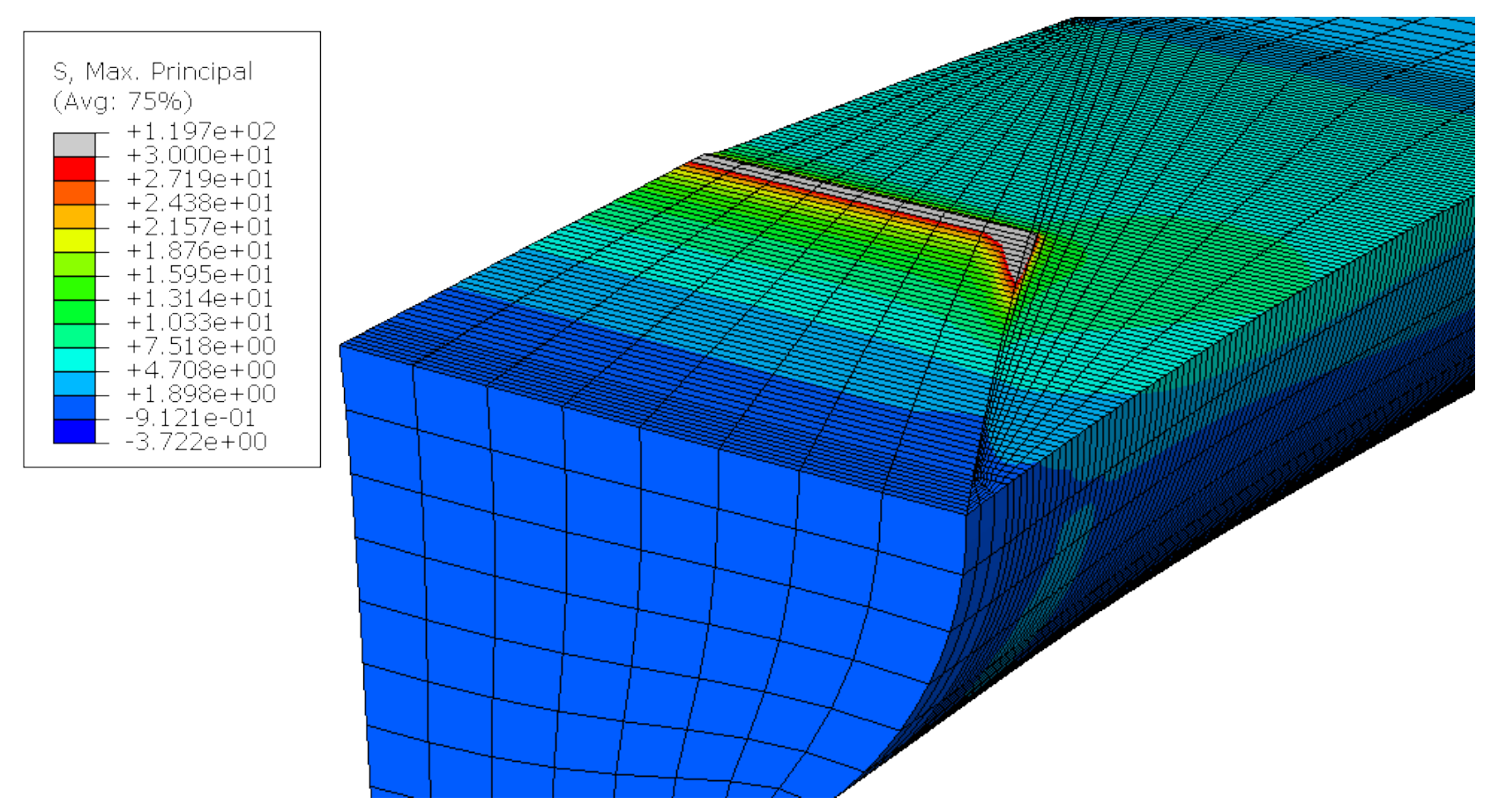

(b) 


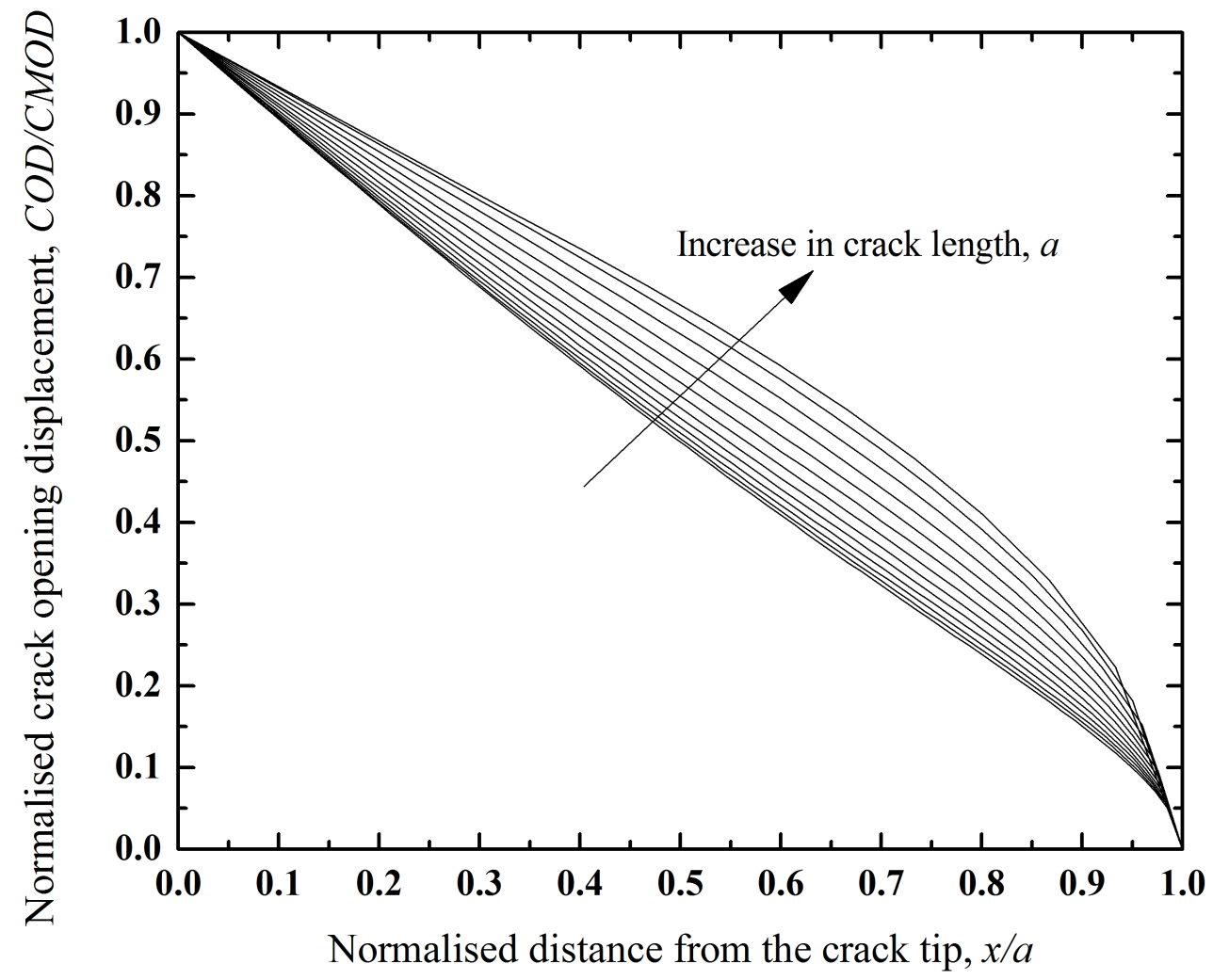

(c)

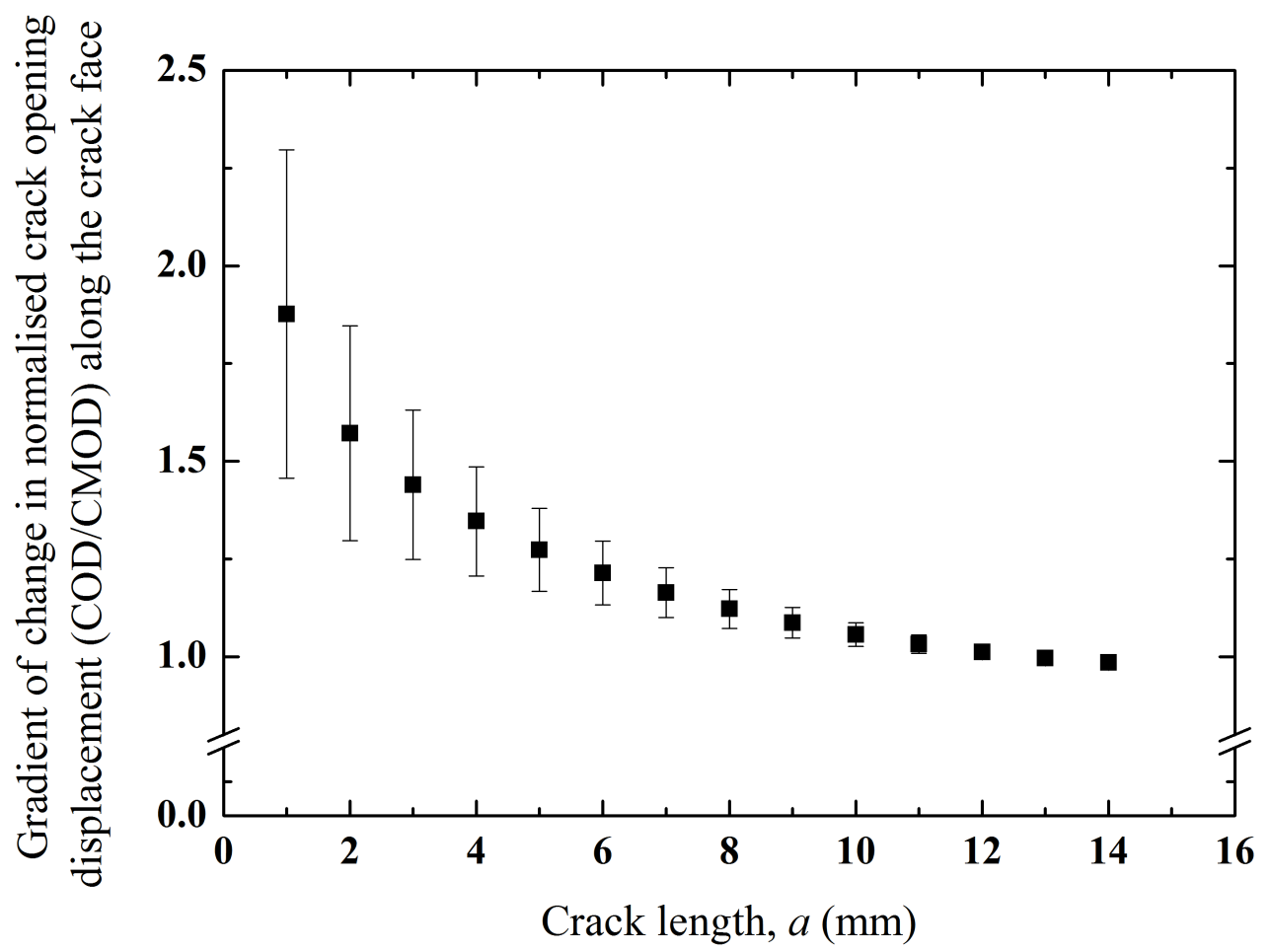

(d) 


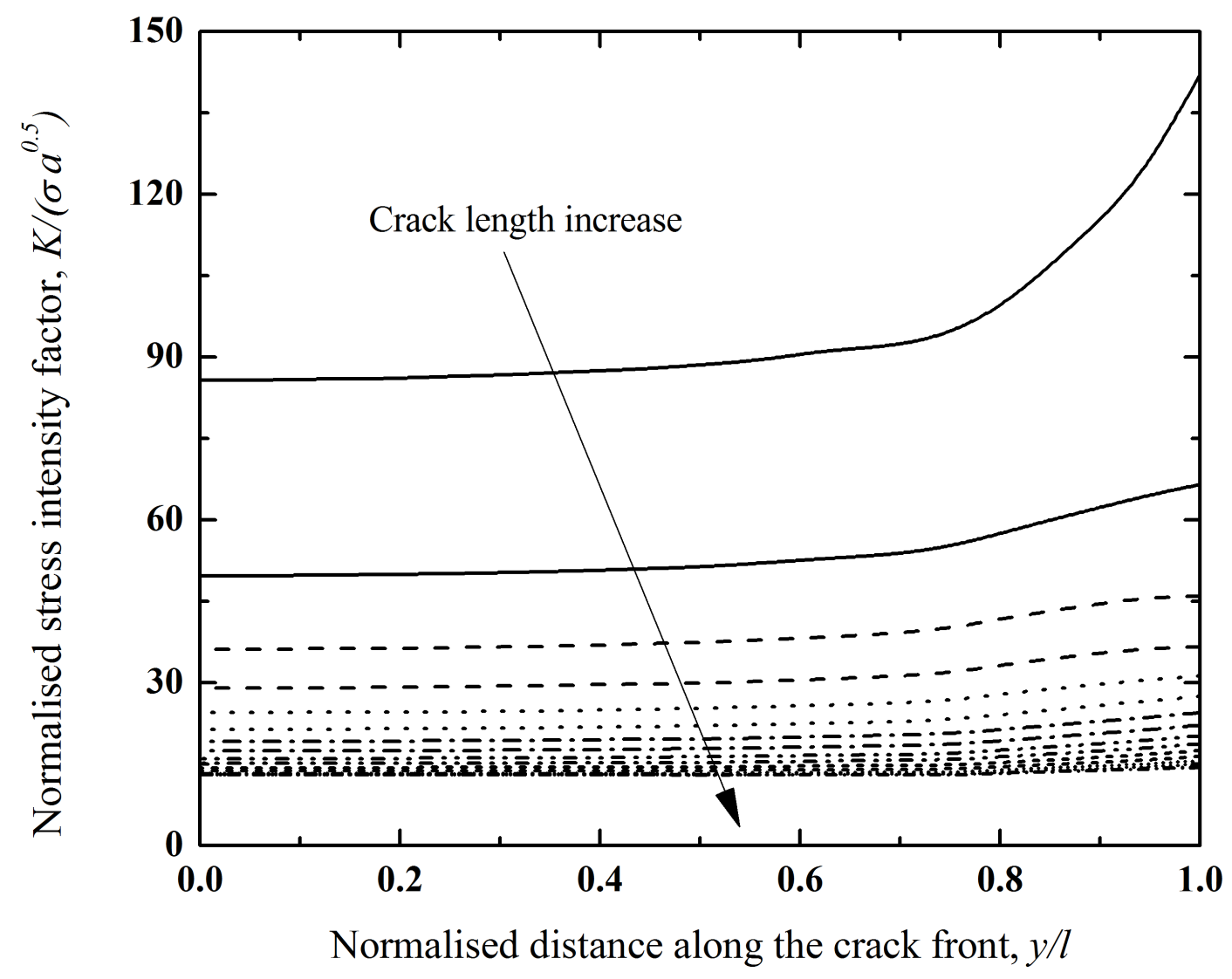

(e)

Fig. 3. Finite element simulation overview (a) the whole model mesh (b) the simple model mesh (c) normalised crack opening profiles along the middle of the specimen at different crack lengths (d) variation of the gradient of the gradient of the line formed from normalised COD vs positions along the crack wake as a function of the crack length (e) distribution of normalised stress intensity factor along the crack front at different crack lengths 


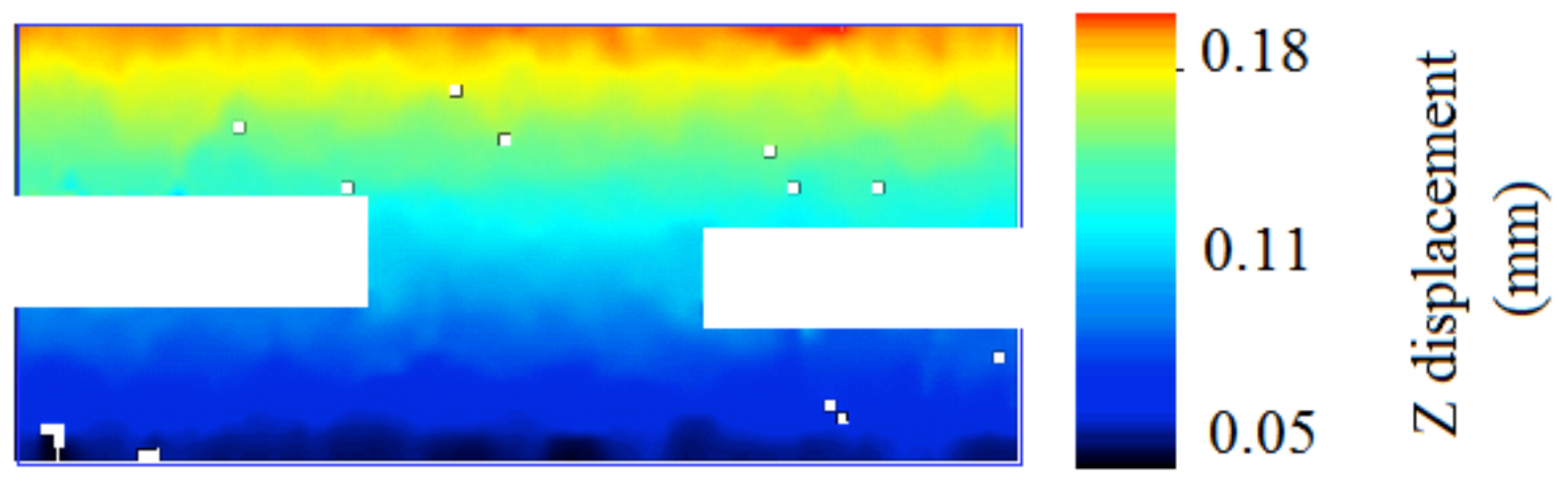

(a)

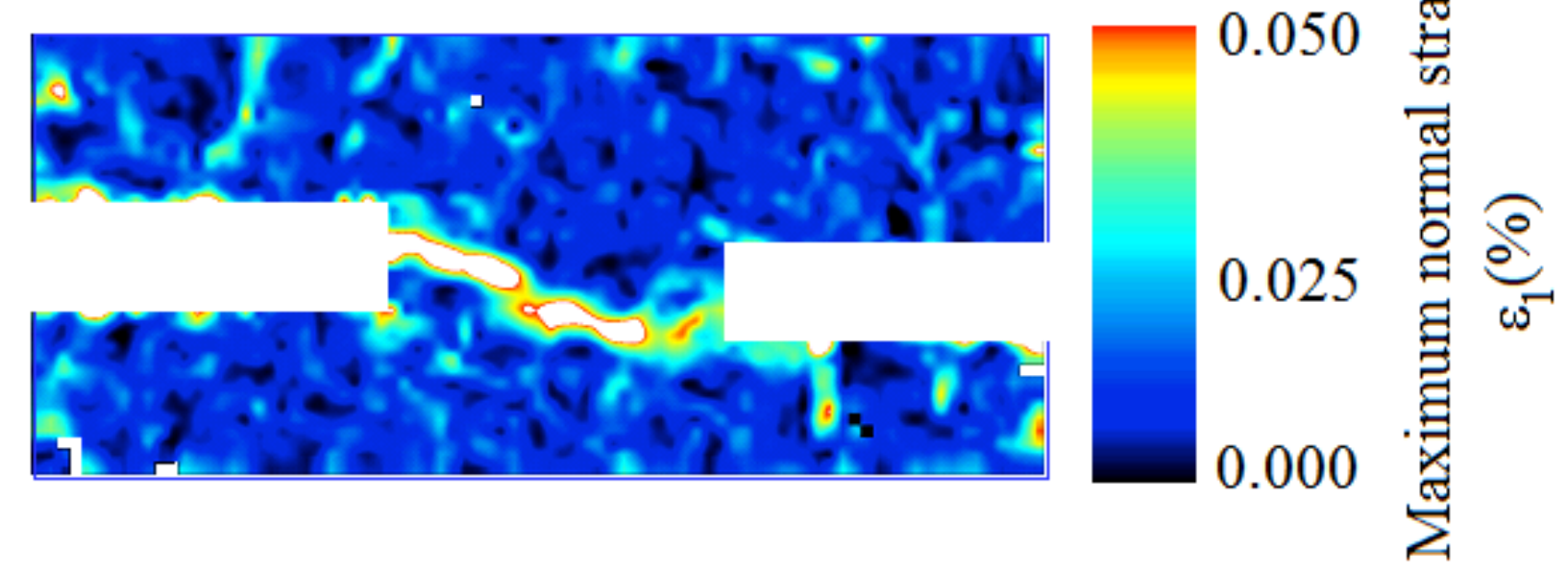

(b)

Fig. 4. Visualisation of the crack following DVC analysis (a) contour of $z$ displacement (i.e. perpendicular to notch plane) in the $y-z$ plane at $x=3 \mathrm{~mm}$ from the tip of the notch (b) contour of maximum normal strain at the same position 

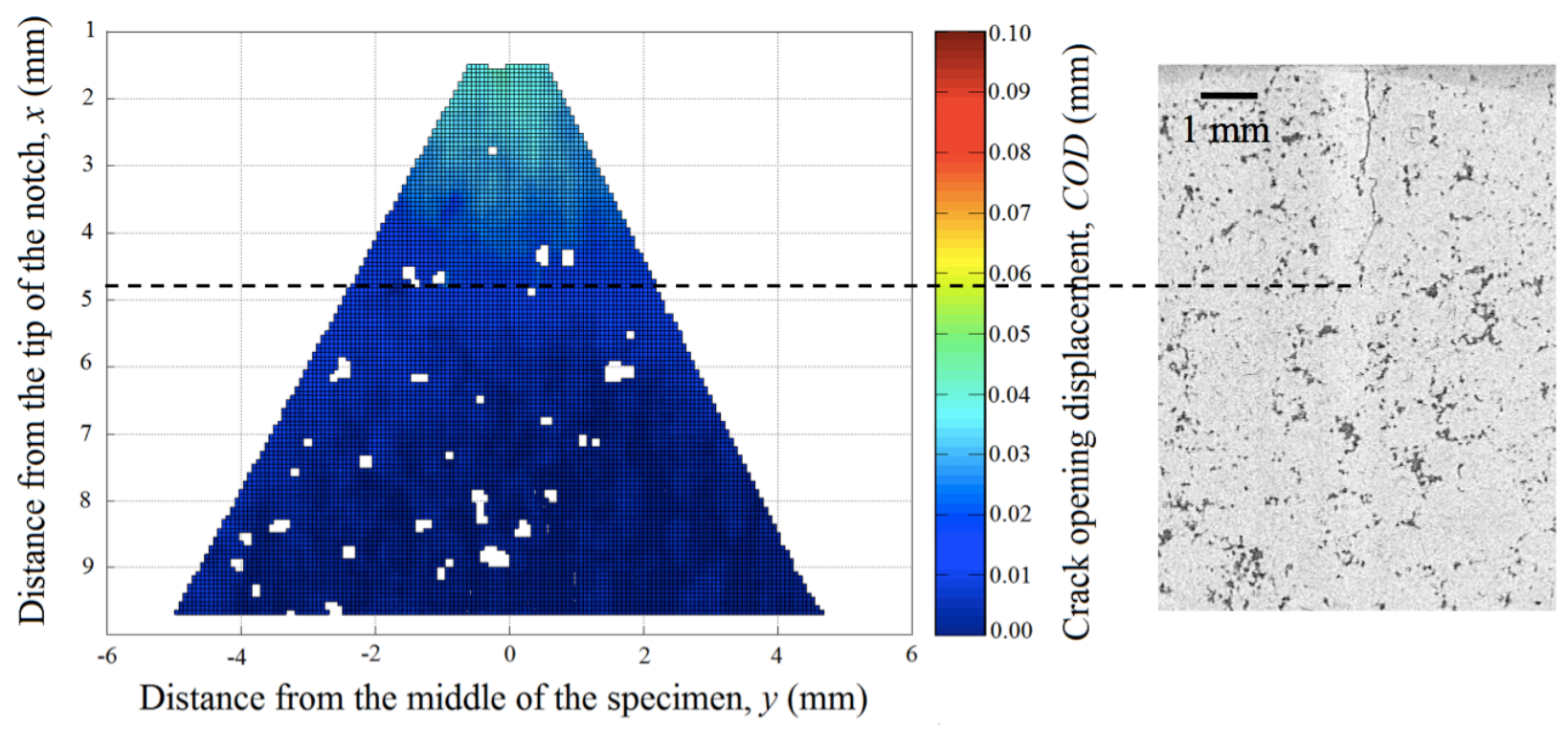

(a) and (b)

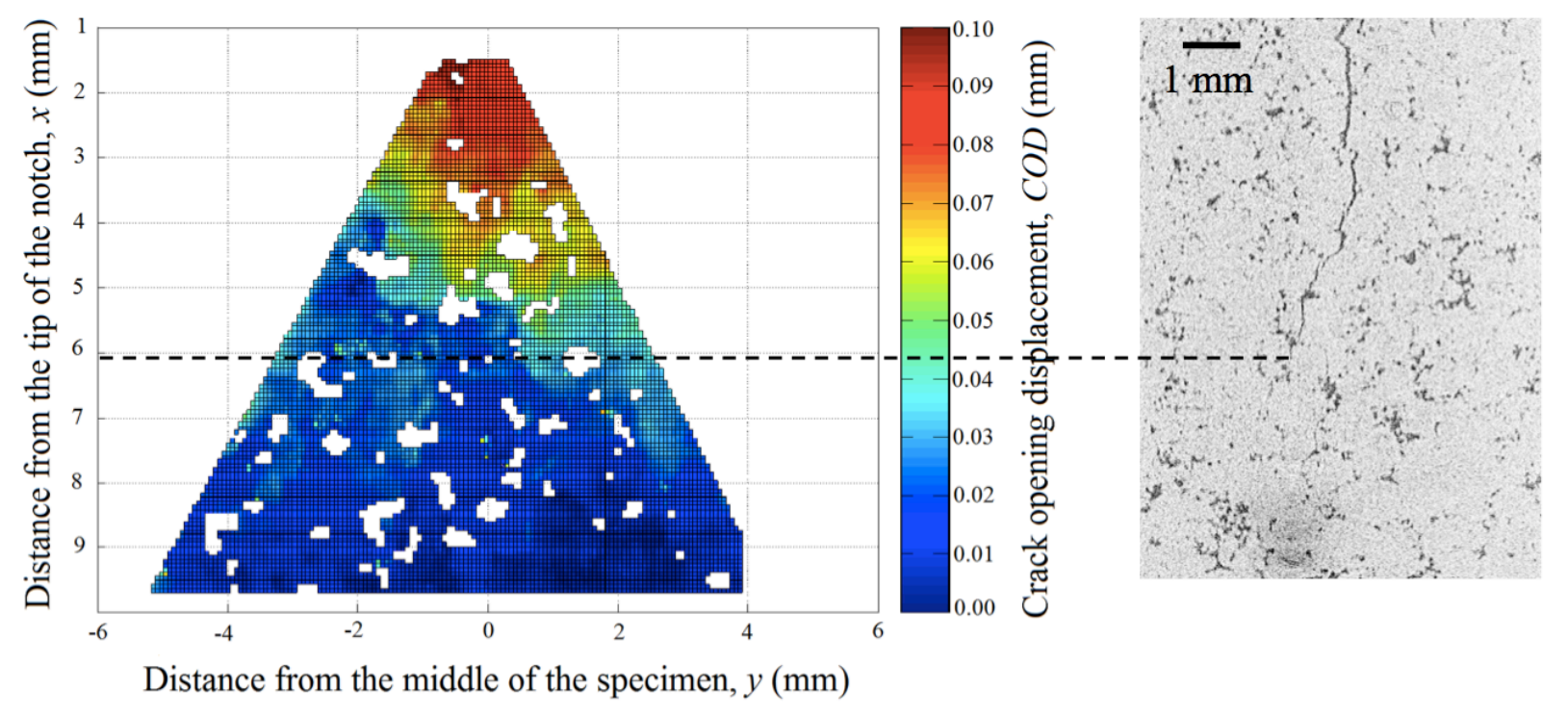

(c) and (d)

Fig. 5. Crack opening displacements and crack length measurement: a) map of the net crack opening displacement ( $\mathrm{mm})$ under load at the first peak load b) virtual slice at the centre of the specimen (XCT); the horizontal line marks the position of the crack tip $(4.8 \mathrm{~mm})$ observed in the XCT image c) map of the net crack opening displacement ( $\mathrm{mm}$ ) under load at the second peak load d) virtual slice at the centre of the specimen (XCT); the horizontal line marks the position of the crack tip $(6.05 \mathrm{~mm})$ observed in the XCT image 


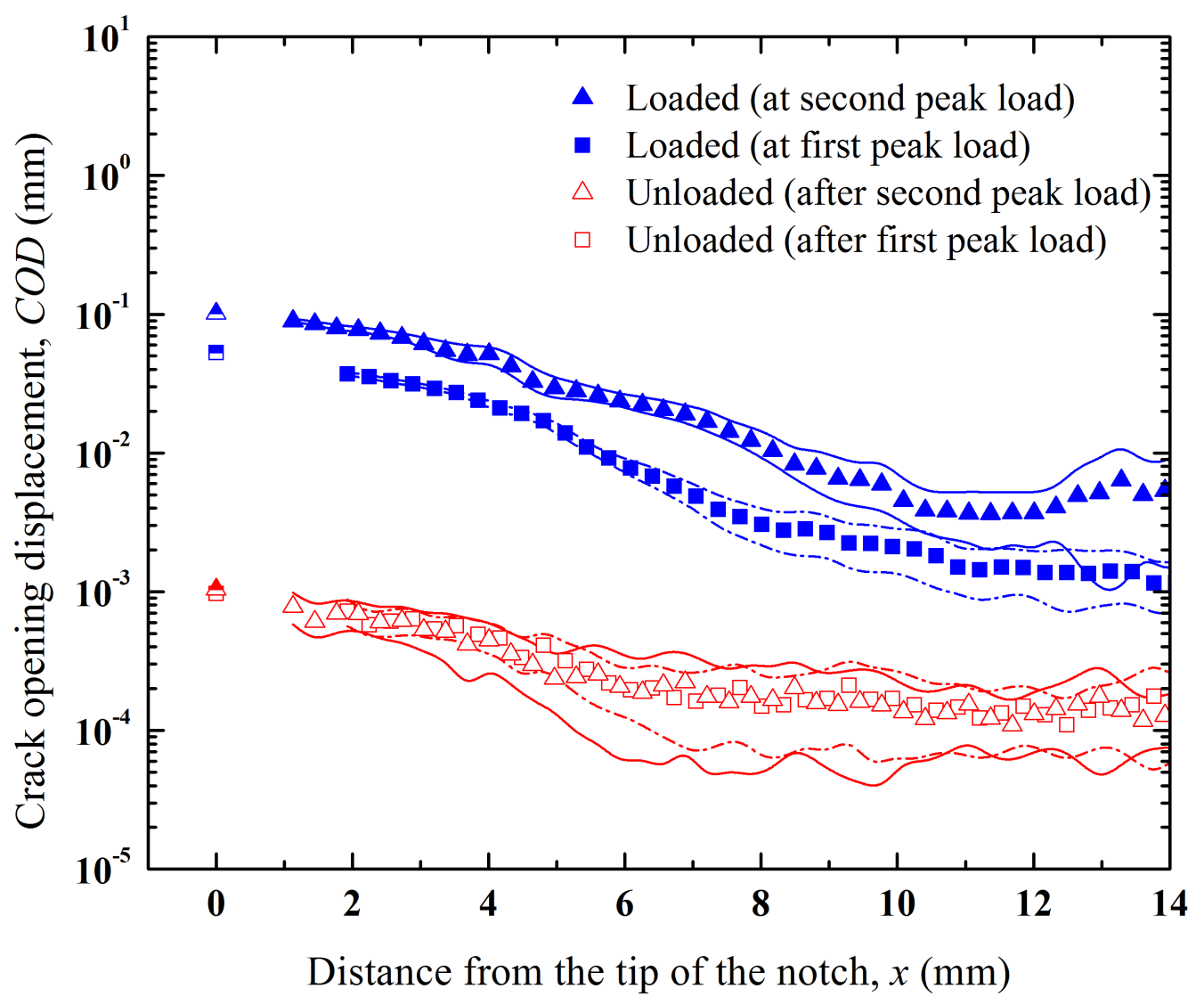

Fig. 6. Distribution of crack opening displacements along the crack under loaded and unloaded conditions - the bounds show the minimum and maximum values of COD along the crack front. Extrapolated CMODs at $x=0$ are shown with half hollow marks. 


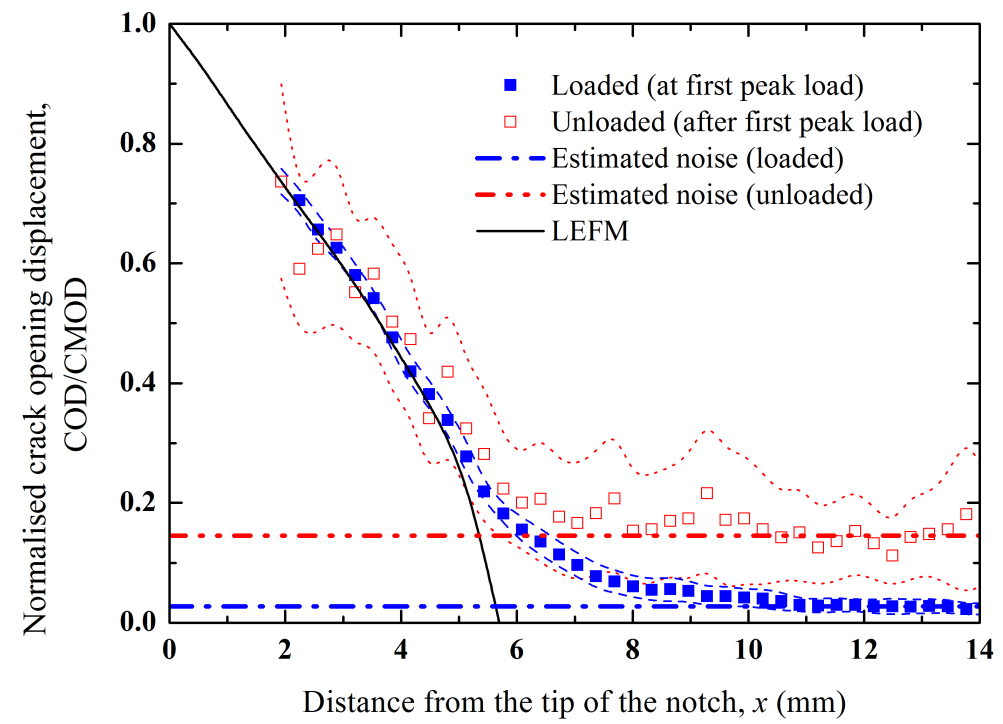

(a)

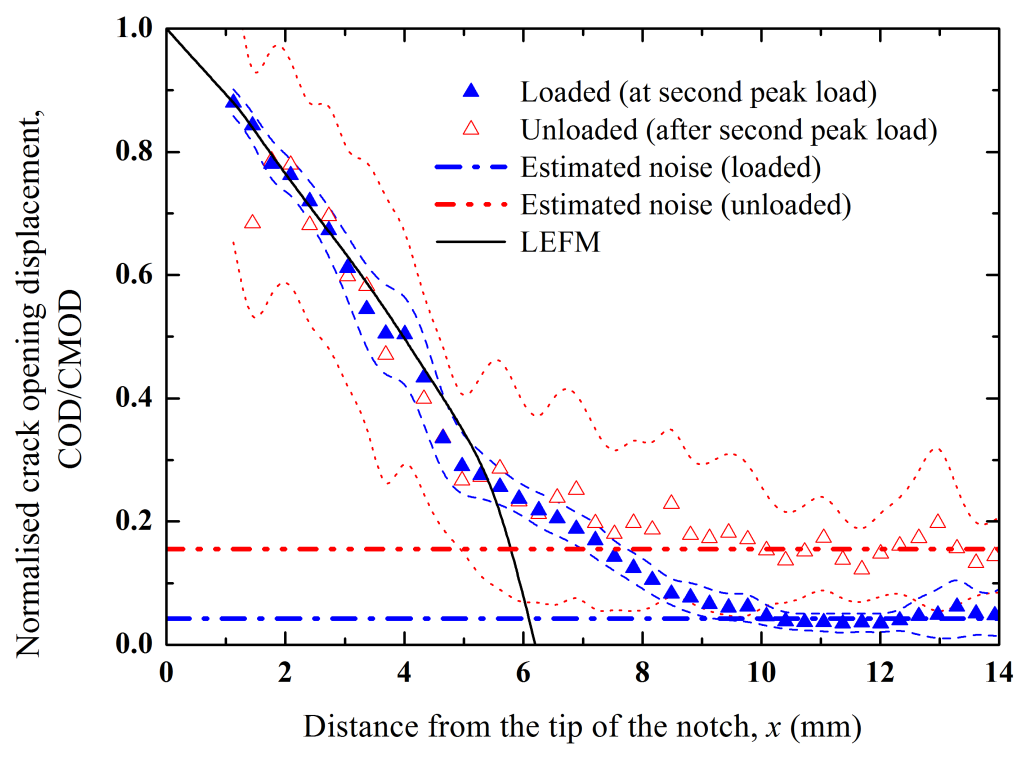

(b)

Fig. 7. Comparison between crack opening profiles of normalised average COD measured by DVC and finite element simulation prediction (a) First loading stage: average crack length is $5.7 \mathrm{~mm}$ and stress intensity factor at the peak load is $K=1.60 \mathrm{MPa}^{1 / 2}$ (b) Second loading stage: average crack length is $6.2 \mathrm{~mm}$ and stress intensity factor at the peak load $K=1.71 \mathrm{MPa} \cdot \mathrm{m}^{1 / 2}$. Estimated noise levels are shown as horizontal lines below which the normalised COD data are not accurate. The range of crack opening along a straight crack front is shown as minimum and maximum lines around the averaged values, which are shown by symbols 